Full length article

\title{
Ultrasound-responsive nutlin-loaded nanoparticles for combined chemotherapy and piezoelectric treatment of glioblastoma cells
}

\author{
Carlotta Pucci ${ }^{\mathrm{a}, 1, *}$, Attilio Marino ${ }^{\mathrm{a}, 1, *}$, Özlem Şen ${ }^{\mathrm{a}, 1}$, Daniele De Pasquale ${ }^{\mathrm{a}, \mathrm{b}}$, \\ Martina Bartolucci ${ }^{c}$, Nerea Iturrioz-Rodríguez ${ }^{a}$, Nicoletta di Leo ${ }^{\mathrm{a}, \mathrm{b}}$, Giuseppe de Vito ${ }^{\text {d,e }}$, \\ Doriana Debellis ${ }^{\mathrm{f}}$, Andrea Petretto ${ }^{\mathrm{c}}$, Gianni Ciofani ${ }^{\mathrm{a}, *}$ \\ a Istituto Italiano di Tecnologia, Smart Bio-Interfaces, Viale Rinaldo Piaggio 34, 56025 Pontedera, Italy \\ b Scuola Superiore Sant'Anna, The Biorobotics Institute, Viale Rinaldo Piaggio 34, 56025 Pontedera, Italy \\ ${ }^{c}$ IRCCS Istituto Giannina Gaslini, Via Gerolamo Gaslini 5, 16147 Genova, Italy \\ d University of Florence, Department of Neuroscience, Psychology, Drug Research and Child Health, Viale Gaetano Pieraccini 6, 50139 Florence, Italy

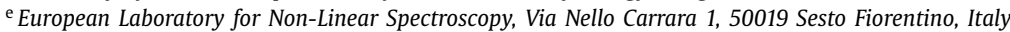 \\ ${ }^{\mathrm{f}}$ Istituto Italiano di Tecnologia, Electron Microscopy Facility, Via Morego 30, 16163 Genova, Italy
}

\section{A R T I C L E I N F O}

\section{Article history:}

Received 8 February 2021

Revised 16 March 2021

Accepted 6 April 2021

Available online 21 April 2021

\section{Keywords:}

Piezoelectric nanoparticles

Nutlin-3a

Ultrasound

Glioblastoma

Drug resistance

\begin{abstract}
A B S T R A C T
Glioblastoma multiforme (GBM), also known as grade IV astrocytoma, represents the most aggressive primary brain tumor. The complex genetic heterogeneity, the acquired drug resistance, and the presence of the blood-brain barrier (BBB) limit the efficacy of the current therapies, with effectiveness demonstrated only in a small subset of patients. To overcome these issues, here we propose an anticancer approach based on ultrasound-responsive drug-loaded organic piezoelectric nanoparticles. This anticancer nanoplatform consists of nutlin-3a-loaded ApoE-functionalized P(VDF-TrFE) nanoparticles, that can be remotely activated with ultrasound-based mechanical stimulations to induce drug release and to locally deliver anticancer electric cues. The combination of chemotherapy treatment with chronic piezoelectric stimulation resulted in activation of cell apoptosis and anti-proliferation pathways, induction of cell necrosis, inhibition of cancer migration, and reduction of cell invasiveness in drug-resistant GBM cells. Obtained results pave the way for the use of innovative multifunctional nanomaterials in less invasive and more focused anticancer treatments, able to reduce drug resistance in GBM.
\end{abstract}

\section{Statement of significance}

Piezoelectric hybrid lipid-polymeric nanoparticles, efficiently encapsulating a non-genotoxic drug (nutlin$3 a)$ and functionalized with a peptide (ApoE) that enhances their passage through the BBB, are proposed. Upon ultrasound stimulation, nanovectors resulted able to reduce cell migration, actin polymerization, and invasion ability of glioma cells, while fostering apoptotic and necrotic events. This wireless activation of anticancer action paves the way to a less invasive, more focused and efficient therapeutic strategy.

(C) 2021 The Authors. Published by Elsevier Ltd on behalf of Acta Materialia Inc. This is an open access article under the CC BY-NC-ND license (http://creativecommons.org/licenses/by-nc-nd/4.0/)

\footnotetext{
the Part of the Special Issue on Conductive and Electroactive Biomaterials and Bioelectronics, guest-edited by Professors Jonathan Rivnay and Mehdi Nikkhah.

* Corresponding author.

E-mail addresses: carlotta.pucci@iit.it (C. Pucci), attilio.marino@iit.it (A. Marino), gianni.ciofani@iit.it (G. Ciofani).

1 These authors equally contributed to this work
}

\section{Introduction}

Glioblastoma multiforme (GBM) is one of the deadliest brain tumors, with a median survival rate of $12-15$ months and a 5-years survival percentage of about 5\% [1]. The gold-standard treatment for GBM combines surgical resection, radiotherapy, and chemotherapy. Nevertheless, currently available therapeutic approaches are extremely inefficient and they only marginally improve the average patient survival [2-4]. Despite the extraordinary effort put into 
finding effective therapeutic strategies, the prognosis for GBM is, at the moment, still very poor. The difficulties in treating GBM arise from its particularly complex and diffuse nature, its invasiveness, and its high genetic heterogeneity [5]. Moreover, the presence of the blood-brain barrier (BBB) prevents most of the drugs from reaching the tumor site [6]; furthermore, the efficacy of the drug treatments able to cross BBB and target the tumor is also limited by the drug resistance mechanisms developed by GBM [7].

Over the past decades, nanotechnology offered effective solutions for the treatment of disparate pathologies owing to the possibilities to improve the systemic delivery of drugs and to enhance their bioavailability $[8,9]$. Moreover, nanoparticles can be engineered to selectively target specific cellular receptors that could enhance their uptake or favor their permeation through the BBB [10]. Active targeting can be achieved by means of different kinds of ligands, but peptides seem to be the most promising due to their stability, low immunogenicity, and easy production $[8,11]$.

An innovative paradigm in cancer nanomedicine regards the development of active nanodevices/nanotransducers able to remotely respond to external stimuli (e.g., magnetic fields, light irradiation and ultrasound, among others), and to convert different forms of energy into physical/chemical anticancer cues (e.g., heat, reactive oxygen species, electric cues) [12-15]. In this regard, piezoelectric nanomaterials represent a promising platform for the non-invasive and remote delivery of local electric cues to cells and tissues [1619]. As a result of the direct piezoelectric effect, these nanotransducers generate electric potentials on their surface in response to mechanical deformations, a phenomenon named mechano-electric transduction. The remote mechanical activation of these materials can be achieved in a non-harmful way by using ultrasounds (US); in the context of cancer therapy, our group demonstrated for the first time the local delivery of anticancer electric cues by using piezoelectric barium titanate nanoparticles in breast cancer [20] and glioblastoma [15] cells. This stimulation approach is similar to that one of the tumor-treating fields [21,22], but it is local and can be specifically targeted to malignant cells, therefore avoiding side effects in healthy tissues/cells (e.g., inhibition of astrocyte proliferation [23]). Chronic piezoelectric stimulation was proven to reduce drug resistance and to inhibit cell proliferation by interfering with $\mathrm{Ca}^{2+}$ and $\mathrm{K}^{+}$homeostasis, and by affecting the organization of mitotic spindles during mitosis $[15,20]$.

Inorganic piezoelectric materials such as barium titanate or zinc oxide have high piezoelectric coefficients, but they raise some concerns about biocompatibility and biodegradability in vivo [24]. On the other hand, despite their slightly lower piezoelectric performances, organic piezoelectric polymers such as poly(vinylidene fluoride) -PVDF- and its copolymer poly(vinylidene fluoride-trifluoro ethylene) $-\mathrm{P}(\mathrm{VDF}-\mathrm{TrFE})$ - represent a valid alternative thanks to their biocompatibility and easier tunability and processing [24]. Pure or composite $\mathrm{P}(\mathrm{VDF}-\mathrm{TrFE})$ films and scaffolds were previously shown to successfully induce cell stimulation and differentiation, in combination with an appropriate US stimulus [25-27]. The grand challenge in organic piezoelectric nanomaterial development is the ability to self-assemble them in small organic nanoparticles while keeping their piezoelectric outputs, without recurring to other inorganic materials to improve the performances. Currently, just two examples can be found in the literature. Xiao et al. successfully implemented a straightforward formulation protocol to produce small nanoparticles of $\mathrm{P}(\mathrm{VDF}-\mathrm{TrFE})$ mainly arranged in the piezoelectric $\beta$-phase [28]. These nanoparticles have been exploited in ferroelectric organic photovoltaic devices and no biological applications were envisaged. More recently, Ma et al. proposed nylon-11 nanoparticles for stem cell osteogenic differentiation upon US exposure [18]. It appears clear, thus, that this research area is still at its very dawn, despite the enormous impact that piezoelectric organic nanoparticles could have in sev- eral technological applications and, as previously shown, in cancer therapy.

In this context, our work aims at providing hybrid lipidpolymer nanocarriers, consisting of a piezoelectric polymeric core and a shell of biocompatible and easily modifiable lipids. Hybrid lipid-polymer nanoparticles combine the advantages of polymeric nanoparticles (structural integrity, superior stability and controlled drug release) and liposomes (higher biocompatibility and biomimetic activity) for an improved therapeutic outcome [29]. Our final piezoelectric nanoparticles, here called PNPs, were composed of a core of $\mathrm{P}(\mathrm{VDF}-\mathrm{TrFE})$, crystallized mainly in its $\beta$-phase, and encapsulating the drug nutlin-3a (Nut), an antagonist of the murine double minute-2 (MDM2) protein, which is a negative regulator of the tumor suppressor protein p53 [30,31]. The polymeric core is surrounded by a shell of 1,2-distearoyl-sn-glycero-3phosphoethanolamine-N-[amino(polyethylene glycol)] (DSPE-PEG), functionalized with a peptide derived from the specific amino acid sequence of the apolipoprotein $\mathrm{E}(\mathrm{ApoE})$ that binds to the low-density lipoprotein receptor (LDLr) of capillary endothelial cells [32]. LDLrs are overexpressed in brain endothelial cells and, therefore, the ApoE-derived peptide should enhance PNP passage through the BBB by transcytosis [33]; moreover, since some LDLrs are also overexpressed in glioblastoma cells, ApoE can potentially favor tumor targeting [34]. In fact, it has been demonstrated that apolipoprotein $\mathrm{E}$ is involved in lipid trafficking within tumors, especially in rapidly growing tumors such as a glioblastoma, making ApoE an interesting potential mediator of GBM targeting [35].

The main goal of this work was to develop an innovative nanotechnology-based anticancer approach to counteract the growth of GBM. The innovative solution mainly consists of a platform based on Nut-loaded ApoE-functionalized P(VDF-TrFE) nanoparticles (PNPs) able to cross the BBB, release the chemotherapy drug, and deliver anticancer electric stimulations to GBM cells. For the first time in the literature, we fabricated, characterized and finally tested the potential of such nanoplatform in relevant in vitro models. After demonstrating the ability of the nanomaterial to cross the BBB in biomimetic dynamic multicellular models, the anticancer potential of the piezoelectric stimulation in combination with the chemotherapy treatment was investigated in terms of apoptosis/necrosis, cell migration, actin polymerization, cell invasiveness, and proteomics in Nut-resistant GBM cells.

\section{Materials and methods}

\subsection{Nanoparticles synthesis}

Hybrid lipid-polymeric piezoelectric nanoparticles were synthesized by following a procedure adapted from a previous work by Xiao et al. [28]. Briefly, $2 \mathrm{~mL}$ of P(VDF-TrFE) (45:65, Piezotech) $(5 \mathrm{mg} / \mathrm{mL}$ ) and $200 \mu \mathrm{L}$ of a solution of nutlin-3a (Nut, $5 \mathrm{mg} / \mathrm{mL}$, Sigma Aldrich) in acetone (Sigma Aldrich) were quickly injected with a syringe into $4.5 \mathrm{~mL}$ of an aqueous dispersion containing DSPE-PEG (1 mg/mL, Nanocs) under vigorous stirring. The above mixture was sonicated for $10 \mathrm{~min}$ in an ice bath (amplitude 70\%) using an ultrasonic tip (Fisherbrand ${ }^{\mathrm{TM}}$ Q125 Sonicator), and then let under agitation for a few hours to evaporate the majority of the organic solvent. Afterward, the mixture was purified with Amicon ${ }^{\circledR}$ centrifuge filters (Ultra-4 Centrifugal Filter Unit [MWCO 100 $\mathrm{kDa}$, Sigma-Aldrich) at $2460 \mathrm{~g}$ for $15 \mathrm{~min}$ at $15^{\circ} \mathrm{C}$. The process was repeated three times, and each time the pellet was redispersed in $4 \mathrm{~mL}$ sterile MilliQ water.

The recrystallization of the polymeric core was performed by refluxing the nanoparticles at $90^{\circ} \mathrm{C}$, above the Curie temperature of P(VDF-TrFE), for $60 \mathrm{~min}$, and then cooling down to room temperature at $1{ }^{\circ} \mathrm{C} / \mathrm{min}$. At the end of the reflux procedure, a total of 1 mg DSPE-PEG or DSPE-PEG/DSPE-PEG-maleimide (1/1) was added 
to further stabilize the nanoparticles, subsequently sonicated for 10 min (amplitude 70\%) using an ultrasonic tip (Fisherbrand ${ }^{\mathrm{TM}}$ Q125 Sonicator). The lipid in excess was removed by three centrifugation steps with Amicon ${ }^{\circledR}$ centrifuge filters (Ultra-4 Centrifugal Filter Unit [MWCO $100 \mathrm{kDa}$ ], Sigma-Aldrich) at $2460 \mathrm{~g}$ for $15 \mathrm{~min}$ at $15^{\circ} \mathrm{C}$.

For the functionalization, $200 \mu \mathrm{L}$ of a $2 \mathrm{mg} / \mathrm{mL}$ aqueous solution of a peptide corresponding to the $141-150$ residues of apolipoprotein $\mathrm{E}$ (ApoE) (GenScript) were added to $4 \mathrm{~mL}$ of the nanoparticles $(2 \mathrm{mg} / \mathrm{mL})$, and let under agitation at $4^{\circ} \mathrm{C}$ for $4 \mathrm{~h}$. Thereafter, functionalized P(VDF-TrFE) nanoparticles (PNPs) were centrifuged 3 times with Amicon ${ }^{\circledR}$ centrifuge filters (Ultra-4 Centrifugal Filter Unit [MWCO $100 \mathrm{kDa}$ ], Sigma-Aldrich) at $2460 \mathrm{~g}$ for $15 \mathrm{~min}$ at $15^{\circ} \mathrm{C}$ to remove unreacted peptide chains.

Empty nanoparticles were prepared following the same protocol, without dissolving nutlin-3a in the initial polymer/acetone solution.

Fluorescent nanoparticles were prepared in the same way, but adding $5 \mu \mathrm{L}$ of fluorescent Vybrant ${ }^{\mathrm{TM}}$ DiO cell-labeling dye (Invitrogen) to the $2 \mathrm{~mL}$ polymer/acetone solution before mixing it with the lipid aqueous dispersion.

\subsection{Electron microscopy}

Scanning electron microscopy (SEM) analysis was performed with a Helios NanoLab 600i FIB/SEM, FEI. A drop of the sample at a concentration of $70 \mu \mathrm{g} / \mathrm{mL}$ was cast on a silicon wafer and let to dry overnight. Thereafter, the sample was gold-sputtered with a Quorum Tech Q150RES Gold Sputter Coater with $30 \mathrm{~mA}$ for $60 \mathrm{~s}$ before the imaging. The morphology and the size of the nanoparticles were evaluated by transmission electron microscopy (TEM). Samples at a concentration of $50 \mu \mathrm{g} / \mathrm{mL}$ were sonicated for $2 \mathrm{~min}$. A drop of the sample was deposited on a $\mathrm{Cu}$ grid (150 mesh) coated with an ultrathin amorphous carbon film. TEM analyses were carried out with a JEOL 1011 operated at $100 \mathrm{kV}$. Annular dark-field (ADF) scanning transmission electron microscopy (STEM) was performed using a JEOL JEM-1400Plus transmission electron microscope with a $\mathrm{LaB}_{6}$ thermionic source, operated at $120 \mathrm{kV}$ using a double-tilt analytical holder. Energy-dispersive X-ray (EDS) analyses have been carried out using a JEOL Dry SD30GV silicondrift detector (SDD), with a $30 \mathrm{~mm}^{2}$ effective area.

The size of the nanoparticles was inferred by measuring their diameter in several SEM and TEM images with ImageJ. Then, a statistical analysis was performed to compute the frequency count with OriginPro 9.1; the same software was used to fit these data with a LogNormal distribution.

\subsection{Dynamic light scattering and $\zeta$-potential measurements}

The hydrodynamic diameter and $\zeta$-potential of nonfunctionalized plain PNPs and PNPs were evaluated with a Zeta-sizer NanoZS90 (Malvern Instruments Ltd). Measurements were performed on dispersions at a concentration of $500 \mu \mathrm{g} / \mathrm{mL}$ at $37^{\circ} \mathrm{C}$. The hydrodynamic diameter was measured at $\mathrm{pH} 4.5$ (in phosphate buffer), at $\mathrm{pH} 7.4$ (in phosphate-buffered saline solution, PBS, Sigma-Aldrich), and in Dulbecco's modified Eagle's medium (DMEM, Sigma-Aldrich) with 10\% fetal bovine serum (FBS, Sigma-Aldrich). All of these conditions were studied with or without $\mathrm{H}_{2} \mathrm{O}_{2}(100 \mu \mathrm{M})$, used to simulate oxidative stress conditions. The $\zeta$-potential was measured only in ultrapure MilliQ water. The software uses the CONTIN analysis to derive the intensity distribution and the cumulant analysis to obtain the hydrodynamic diameter and the polydispersity index.

\subsection{Fourier-transformed infrared and Raman spectroscopy}

Fourier-transformed infrared (FTIR) spectroscopy was performed to highlight the characteristic peaks of $\mathrm{P}(\mathrm{VDF}-\mathrm{TrFE})$ and plain PNPs using a Shimadzu Miracle 10 on freeze-dried samples. Spectra were collected in the range of $450-1500 \mathrm{~cm}^{-1}$ with a resolution of $2 \mathrm{~cm}^{-1}$ and are the average result of 16 scans.

The fraction of $\mathrm{P}(\mathrm{VDF}-\mathrm{TrFE})$ in the $\beta$-phase, $F(\beta)$, with respect to the $\alpha$-phase, was evaluated by comparing the intensity of the characteristic peaks of the two phases $\left(765 \mathrm{~cm}^{-1}\right.$ for the $\beta$-phase and $840 \mathrm{~cm}^{-1}$ for the $\alpha$-phase) using the formula [36,37]:

$F(\beta)=\frac{A_{\beta}}{\left(\frac{K_{\beta}}{K_{\alpha}}\right) A_{\alpha}+A_{\beta}}$

where $A_{\alpha}$ and $A_{\beta}$ represent the absorbance at 765 and $840 \mathrm{~cm}^{-1}$, respectively, while $K_{\alpha}$ and $K_{\beta}$ are the corresponding absorption coefficients $\left(K_{\alpha}=6.1 \cdot 10^{4} \mathrm{~cm}^{2} / \mathrm{mol}\right.$ and $\left.K_{\beta}=7.7 \cdot 10^{4} \mathrm{~cm}^{2} / \mathrm{mol}\right)$ [38].

Raman spectroscopy (LabRAM HR Evolution; Horiba) was first performed to analyze the crystalline structure of both P(VDF-TrFE) alone and in plain PNPs; an estimate of $\beta$-phase content with respect to the $\alpha$-phase $(\beta / \alpha)$ was obtained by dividing the intensity of the Raman peak at $848 \mathrm{~cm}^{-1}$, corresponding to the $\beta$-phase $\left(I_{\beta}\right)$, by the intensity of the Raman peak at $803 \mathrm{~cm}^{-1}$, corresponding to the $\alpha$-phase $\left(I_{\alpha}\right)$, as reported in the literature [38].

\subsection{Thermogravimetric analysis and differential scanning calorimetry}

Thermogravimetric analysis (TGA) was carried out to determine the percentage of each component (namely, P(VDF-TrFE) and DSPEPEG) in plain PNPs with a Q500 analyzer (TA Instrument), by heating the samples from 30 to $700^{\circ} \mathrm{C}$ at a heating rate of $5^{\circ} \mathrm{C} / \mathrm{min}$ under nitrogen atmosphere (flow rate of $50 \mathrm{~mL} / \mathrm{min}$ ).

Differential scanning calorimetry (DSC) curves were obtained using a DSC-1 STARe System (Mettler Toledo) to obtain information regarding the thermal behavior of P(VDF-TrFE), DSPE-PEG, and plain PNPs. The DSC analysis has been performed on $1 \mathrm{mg}$ of freeze-dried samples from 20 to $200^{\circ} \mathrm{C}$ at a heating rate of $10^{\circ} \mathrm{C} / \mathrm{min}$. The reported thermograms represent the first heating ramp to portray the crystallinity of the obtained nanoparticles, avoiding the reorganization in bigger aggregates due to the melting phenomenon that could result into the second heating ramp.

\subsection{Functionalization assessment}

The presence of the ApoE peptide on the surface of the nanoparticles was evaluated by fluorescence spectroscopy, exploiting the fluorescence of the tryptophan residue in the peptide [32]. A Cary Eclipse fluorescence spectrofluorimeter (Agilent Technologies) was used to measure the emission signal in the range $300-$ $440 \mathrm{~nm}$, after excitation at $280 \mathrm{~nm}$. The wt\% of the peptide on the nanoparticles was evaluated by comparing the emission intensity at $350 \mathrm{~nm}$ of PNPs with a calibration curve of the free peptide in Milli-Q water. PNPs spectra were first normalized by that of the non-functionalized nanoparticles to avoid any contribution due to background scattering.

Sodium dodecyl sulfate-poly(acrylamide) gel electrophoresis (SDS-PAGE) was carried to further confirm the presence and quantify the amount of ApoE on PNPs [39]. $22.5 \mu \mathrm{L}$ of ApoE, PNPs, or plain PNPs were mixed with $7.5 \mu \mathrm{L}$ of Laemmli buffer (BioRad) and heated for $10 \mathrm{~min}$ at $95^{\circ} \mathrm{C}$ to favor denaturation. The samples $(30 \mu \mathrm{L})$ were loaded into a $4-15 \%$ Mini-PROTEAN TGX Precast Protein Gel (BioRad) previously placed in an electrophoresis 
cell (Mini-PROTEAN Tetra Cell, BioRad) filled with Tris/Glycine running buffer (BioRad). A molecular weight marker (PageRuler Plus Prestained Protein Ladder, Thermo Fisher Scientific) was also run in parallel. The gel was run at $100 \mathrm{~V}$ for $1 \mathrm{~h}$ and then stained with Coomassie Blue for $1 \mathrm{~h}$ under agitation. The gel was then rinsed twice with a de-staining solution (10\% glacial acetic acid, $40 \% \mathrm{H}_{2} \mathrm{O}, 50 \%$ methanol) for $20 \mathrm{~min}$ to remove unspecific staining, and finally washed with Milli-Q water. The bands, corresponding to the peptide, were analyzed with the software Image (https: //imagej.nih.gov/ij/) and the quantification was made by comparing the intensity of the bands corresponding to PNPs to those of known concentrations of plain peptide.

The ApoE amount on PNPs was also measured by BCA assay Protein Kit (Thermo Scientific). $25 \mu \mathrm{L}$ of $16 \mathrm{mg} / \mathrm{mL}$ PNPs or plain PNPs were mixed with $200 \mu \mathrm{L}$ of working solution. The samples were then incubated at $37^{\circ} \mathrm{C}$ for $30 \mathrm{~min}$, and the absorbance at $560 \mathrm{~nm}$ of $90 \mu \mathrm{L}$ of the samples was measured in triplicate with a VICTOR X3 (PerkinElmer) plate reader. The wt\% of ApoE on the nanoparticles was evaluated by using a calibration curve of the free peptide in water (concentration range $0-250 \mu \mathrm{g} / \mathrm{mL}$ ).

\subsection{High-performance liquid chromatography}

The loading and the release of nutlin-3a from Nut-loaded PNPs (Nut-PNPs) were quantified by high-performance liquid chromatography (HPLC) with a Shimadzu LC-20AT, using a C-18 column (150 $\mathrm{mm} \times 4.6 \mathrm{~mm}$ i.d., $5 \mu \mathrm{m}$ particle size). A mobile phase of $80 \%$ methanol (for HPLC, $\geq 99.9 \%$, Sigma-Aldrich) and 20\% $\mathrm{H}_{2} \mathrm{O}$ (HPLC Plus, Sigma-Aldrich) was pumped in isocratic mode at a flow rate of $1 \mathrm{~mL} / \mathrm{min}$. The retention time of nutlin-3a was $4.77 \mathrm{~min}$ and its intensity was monitored by a UV detector at $260 \mathrm{~nm}$.

For the drug loading quantification, $1 \mathrm{mg}$ of freeze-dried NutPNPs were dissolved in $400 \mu \mathrm{L}$ of acetonitrile and left in agitation at $37^{\circ} \mathrm{C}$ for $3 \mathrm{~h}$. Afterward, $100 \mu \mathrm{L}$ of cold ultrapure water were added and the sample centrifuged at $16000 \mathrm{~g}$ for $90 \mathrm{~min}$ at $4^{\circ} \mathrm{C}$. The supernatant was collected and measured with HPLC. The drug loading (\%) was calculated using the formula:

Drug loading $(\%)=\frac{\text { Nutlin mass in LMNVs }(\mathrm{mg})}{\text { Total mass of LMNVs }(\mathrm{mg})} \cdot 100$

Release studies were performed by dissolving $1 \mathrm{mg}$ of NutPNPs either at $\mathrm{pH} 7.4$ (PBS) to simulate the physiological environment or at $\mathrm{pH} 4.5$ to simulate the $\mathrm{pH}$ of the microenvironment of cancer cells or of acidic organelles. The samples were left under agitation at $37^{\circ} \mathrm{C}$ and centrifuged with Amicon ${ }^{\circledR}$ centrifuge filters (Ultra-4 Centrifugal Filter Unit [MWCO $100 \mathrm{kDa}$ ], Sigma-Aldrich) at $2460 \mathrm{~g}$ for $15 \mathrm{~min}$ at $15^{\circ} \mathrm{C}$ at 24 and $48 \mathrm{~h}$. The filtrates at the bottom of the Amicon tubes were collected and measured with HPLC to quantify the amount of nutlin-3a, whereas the pellets were re-dispersed in their buffers. To study the effect of the application of the ultrasound stimulus on the release profile, $1 \mathrm{mg} / \mathrm{mL}$ of Nut-PNPs at $\mathrm{pH} 7.4$ or 4.5 were stimulated for $1 \mathrm{~h}$ with $1 \mathrm{~W} / \mathrm{cm}^{2}$ intensity and $1 \mathrm{MHz}$ frequency, at 24 and $48 \mathrm{~h}$ time points. Single US stimuli were activated every $2 \mathrm{~s}$ and lasted $200 \mathrm{~ms}$ each (the same protocol used for the cell stimulation).

\subsection{Blood-brain barrier model crossing evaluation}

To evaluate the efficiency of non-functionalized plain PNPs and PNPs to cross an in vitro model of the BBB, an ad hoc bioreactor designed by our group was used [39,40]. The bioreactor in poly(methylmethacrylate) (PMMA) and poly(dimethylsiloxane) (PDMS) is composed of an upper channel (18.6 mm long, $5 \mathrm{~mm}$ large, and $0.5 \mathrm{~mm}$ high) that mimics the endothelial lumen, and of a bottom chamber $\left(2 \mathrm{~mm}\right.$ high, with a total surface of $20 \mathrm{~mm}^{2}$ ), which represents the other side of the BBB (Fig. S1). The two chambers are separated by a poly(ethylene terephthalate) (PET) transparent membrane with pores of $3 \mu \mathrm{m}$, on top of which human endothelial cells hCMEC/D3 (Sigma-Aldrich) $\left(5 \cdot 10^{4}\right.$ cells $\left./ \mathrm{cm}^{2}\right)$ in EndoGRO-MV-VEGF medium (Merck Millipore) with 2.5\% FBS and $1 \%$ penicillin-streptomycin $(\mathrm{P} / \mathrm{S}, \mathrm{Gybco})$ were seeded, whereas the other side was populated with human brain-derived astrocytes HA (Cliniscience) $\left(8 \cdot 10^{3}\right.$ cells $\left./ \mathrm{cm}^{2}\right)$ in Astrocyte Growth Medium (Cliniscience), 1 day after hCMEC/D3 seeding. The BBB crossing experiments were performed when hCMEC/D3 formed a monolayer, which occurs after 5 days from the seeding procedure.

Transendothelial electrical resistance (TEER) measurements (with a Millipore Millicell ERS-2 Volt-Ohmmeter) were performed to check the quality of the BBB [41], whereas the apparent permeability $\left(P_{a p p}\right)$ and the endothelial permeability coefficient $\left(P_{e}\right)$ to a $100 \mu \mathrm{g} / \mathrm{mL}$ rhodamine B-dextran (70 kDa, Invitrogen) solution in complete medium were calculated as reported in the literature $[42,43]$.

Due to the specific geometry of the upper chamber, the reproduction of the typical shear stress experienced by brain capillaries (about $10 \mathrm{dyn} / \mathrm{cm}^{2}$ ) was guaranteed by the application of a flow of $12 \mathrm{~mL} / \mathrm{min}$ [44]. A dispersion of either plain PNPs or functionalized PNPs labeled with Vybrant ${ }^{\mathrm{TM}}$ DiO in DMEM with $4.5 \mathrm{~g} / \mathrm{L}$ of glucose, $5 \%$ of FBS and 5\% of HEPES was perfused thanks to an Ibidi Pump for $3 \mathrm{~h}$. Thereafter, the upper side of the fluidic unit was washed and left in $500 \mu \mathrm{L}$ of the same medium used during the experiment; the medium was replaced daily for a total of 48 h. At the end of the experiment, the solution in the bottom chamber was collected and the fluorescence due to nanoparticle presence ( $\lambda_{e x} 485 \mathrm{~nm}, \lambda_{e m} 535 \mathrm{~nm}$ ) was measured with a VICTOR X3 plate reader (PerkinElmer). The concentration of Vybrant ${ }^{\mathrm{TM}}$ DiOlabeled nanoparticles in the lower chamber of the fluidic unit was evaluated by comparing their emission intensity with a calibration curve obtained with known concentrations of the same nanoparticles used for the experiment.

Images of the BBB model were obtained by $\mathrm{C} 2 \mathrm{~s}$ confocal microscope (Nikon). Briefly, at the end of the experiment, the BBBs treated with nanoparticles were fixed with $4 \%$ paraformaldehyde (PFA) for $20 \mathrm{~min}$, washed, and stained with TRITC-phalloidin (1:100, Sigma-Aldrich) and Hoechst 33342 (1:1000, Invitrogen) for $2 \mathrm{~h}$.

\subsection{Drug and nanoparticle testing in glioblastoma cell lines}

T98G (ATCC® CRL-1690 ${ }^{\mathrm{TM}}$ ), U251 MG (Merck), and U87 MG (ATCC ${ }^{8}$ HTB-14 ${ }^{\mathrm{TM}}$ ) glioblastoma cell lines were cultured in T75 flasks with DMEM, supplemented with $10 \%$ FBS (Gibco), $100 \mathrm{IU} / \mathrm{mL}$ penicillin (Gibco), and $100 \mu \mathrm{g} / \mathrm{mL}$ streptomycin (Gibco). Cells were cultured by keeping a $20-85 \%$ confluency range and then seeded in 24 multiwell at a density of $2 \cdot 10^{4}$ cells $/ \mathrm{cm}^{2}$ for drug and nanoparticle testing. Concerning Nut treatment, the effect of different drug concentrations $(0.2,1.0,5.0,25.0 \mu \mathrm{M} ; 48 \mathrm{~h}$ incubation) and of the vehicle (dimethylsulfoxide -DMSO-, 1:185 dilution in the complete medium; $48 \mathrm{~h}$ incubation) on cell metabolism has been analyzed by using the WST-1 Assay Reagent (2-(4-iodophenyl)-3(4-nitrophenyl)-5-(2,4-disulfophenyl)-2H-tetrazolium sodium salt; BioVision), similarly as previously described [45]. Briefly, cultures were rinsed with PBS and then incubated with the WST1 reagent (1:11 dilution in phenol red-free complete medium for $45 \mathrm{~min}$ at $37^{\circ} \mathrm{C}$ ). At the end of the reagent incubation, supernatants were collected and absorbance was measured at 450 nm with a Perkin Elmer VICTOR X3 UV-Vis spectrophotometer. The absorbance of the plain phenol red-free medium (blank) was subtracted from measurements. Finally, absorbance data were normalized to the non-treated controls. Following the same experimental procedures, the toxicity of PNPs and Nut-PNPs (100, 
250, 500, $1000 \mu \mathrm{g} / \mathrm{mL} ; 48 \mathrm{~h}$ incubation) has been assessed. Since the most interesting results were found in T98G cells -this cell line was found to be resistant to free-Nut but sensitive to Nut-PNPs-, the following investigations have been carried out on these cells.

\subsection{Nanoparticle internalization: Confocal fluorescence and Raman imaging}

For confocal fluorescence microscopy imaging, T98G cells were seeded on $\mu$-Plate 24 Well (Ibidi, seeding density of $2 \cdot 10^{4}$ cells $\left(\mathrm{cm}^{2}\right)$. At $12 \mathrm{~h}$ from seeding, cells were incubated for 24 and $72 \mathrm{~h}$ with $500 \mu \mathrm{g} / \mathrm{mL}$ Vybrant ${ }^{\mathrm{TM}}$ DiO-labeled PNPs and then fixed with $4 \%$ PFA in PBS for $20 \mathrm{~min}$ at $4^{\circ} \mathrm{C}$. Cultures were then stained with TRITC-phalloidin (1:100 in PBS, Sigma-Aldrich) and Hoechst 33342 (1:1000 in PBS, Invitrogen) for $2 \mathrm{~h}$. Samples were finally rinsed with PBS and imaged with a C2s confocal microscope (Nikon). 3D image reconstruction was finally performed by using NIS Elements Software (Nikon).

Concerning confocal Raman imaging, T98G cells were seeded on Raman grade calcium fluoride substrates (Crystran, seeding density $2 \cdot 10^{4}$ cells $/ \mathrm{cm}^{2}$ ). At $12 \mathrm{~h}$ from seeding, cells were incubated for 24 $\mathrm{h}$ with $500 \mu \mathrm{g} / \mathrm{mL}$ PNPs and then fixed with 4\% PFA in PBS for 20 min at $4{ }^{\circ} \mathrm{C}$. Cultures were dehydrated and then imaged with a confocal Raman microscope (LabRAM HR Evolution, Horiba). LabSpec 6 software has been used to obtain the signal maps; signals of the PNPs ( $\beta$-phase: $820 \mathrm{~cm}^{-1}>$ Raman shift $>880 \mathrm{~cm}^{-1}$ ), cell proteins (amide I region [46]: $1600 \mathrm{~cm}^{-1}>$ Raman shift $>1700$ $\mathrm{cm}^{-1}$ ), and nuclei (DNA [47,48]: $760 \mathrm{~cm}^{-1}>$ Raman shift $>790$ $\mathrm{cm}^{-1}$ ) were used, with a pixel intensity proportional to the integrated peak area.

\subsection{Calcium imaging during piezoelectric stimulation}

T98G cells were seeded on WillCo-dish ${ }^{\circledR}$ glass bottom dishes (seeding density $2 \cdot 10^{4}$ cells $/ \mathrm{cm}^{2}$ ). At $12 \mathrm{~h}$ from seeding, cells were incubated for $24 \mathrm{~h}$ with $500 \mu \mathrm{g} / \mathrm{mL}$ PNPs. Before imaging, cells were incubated with Fluo-4 AM (Invitrogen; $1 \mu \mathrm{M}$ in DMEM, 30 min incubation at $37^{\circ} \mathrm{C}$ ) and then the solution was replaced with phenol red-free DMEM supplemented with HEPES (Thermo Fisher). Time-lapse imaging was carried out with a confocal laser scanning microscopy (C2s confocal microscope, Nikon) by using a perfect focus system (Nikon). Before starting the stimulation, cells were maintained for 20 min to complete the de-esterification of the AM groups of the fluorescent dye. During $\mathrm{Ca}^{2+}$ imaging, US were generated by a KTAC-4000 device (Sonidel) equipped with a S-PW $3 \mathrm{~mm}$ diameter tip. Chronic US stimulation was performed following a previously described protocol, which is known to activate piezoelectric nanoparticles without inducing detectable temperature increases of the cell medium $[15,49]$. Briefly, trains of US were delivered with $1 \mathrm{~W} / \mathrm{cm}^{2}$ intensity and $1 \mathrm{MHz}$ frequency. US were delivered starting at $t=500 \mathrm{~s}$ of the time-lapse imaging. Single stimuli were activated every $2 \mathrm{~s}$ and lasted $200 \mathrm{~ms}$ each.

Fluorescence intensities $(F)$ were calculated as the mean pixel value in the intracellular region of interest (ROI), once subtracted the extracellular background. The fluorescence intensity at time $t=0 \mathrm{~s}$ was indicated as $F_{0}$; The $F / F_{0}$ trace of the cells incubated with PNPs and stimulated with US (PNPs + US) was reported in a graph and compared to that one of cultures stimulated with US without the presence of nanoparticles (US). Representative $F / F_{0}$ images at $t=8 \mathrm{~min}, t=33 \mathrm{~min}, t=60$ min, and $t=85 \mathrm{~min}$ of the time-lapse $\mathrm{Ca}^{2+}$ imaging were obtained with Image software by using the divide function of the Math process after background subtraction, as previously described [20].

\subsection{Investigations on cell apoptosis and necrosis}

T98G cells were seeded in 24 multiwell at a density of $2 \cdot 10^{4}$ cells $/ \mathrm{cm}^{2}$. At $12 \mathrm{~h}$ from seeding, cultures were organized in 8 experimental classes: controls without (Control) or with (Control + US) US stimulation, cells incubated with free Nut without (Nut) or with (Nut + US) US stimulation, cells incubated with PNPs without (PNPs) or with (PNPs + US) US stimulation, and cells incubated with Nut-PNPs without (Nut-PNPs) or with (NutPNPs + US) US stimulation. Both PNPs and Nut-PNPs were used at $500 \mu \mathrm{g} / \mathrm{mL}$; concerning the Nut and Nut + US experimental classes, the free drug was at concentration $21.5 \mu \mathrm{M}$, which corresponds to the amount of Nut loaded in $500 \mu \mathrm{g} / \mathrm{mL}$ of Nut-PNPs. US were delivered following the stimulation protocol described above in section 2.11, $1 \mathrm{~h}$ per day for 2 days.

After $12 \mathrm{~h}$, samples were washed in PBS, treated with trypsin for $5 \mathrm{~min}$ at $37^{\circ} \mathrm{C}$, centrifuged, and finally resuspended in the $1 \times$ annexin $\mathrm{V}$ binding buffer supplemented with $1 \mu \mathrm{g} / \mathrm{mL}$ of propidium iodide (PI) and $2.5 \mu \mathrm{M}$ annexin V-FITC (15 min at $37^{\circ} \mathrm{C}$ ). The suspension of stained cells was then analyzed by flow cytometry as previously described [50]. Specifically, the fluorescence intensity of the cells was measured with a Beckman Coulter CytoFLEX (for annexin V-FITC: $\lambda_{e x} 488 \mathrm{~nm}, \lambda_{e m} 525 \pm 40 \mathrm{~nm}$; for PI: $\lambda_{e x} 488 \mathrm{~nm}, \lambda_{e m} 690 \pm 50 \mathrm{~nm}$ ); the percentages of necrotic, late apoptotic, early apoptotic and healthy cell populations were analyzed using the CytoFLEX software.

\subsection{Migration and invasion assays}

A scratch assay was performed to assess the migration rate of T98G cells in the 8 previously described experimental classes (Control, Nut, PNPs, Nut-PNPs, Control + US, Nut + US, PNPs + US, Nut-PNPs + US). T98G cells were seeded in Culture Insert 2 Well systems (Ibidi) with a $5.5 \cdot 10^{4}$ cells $/ \mathrm{cm}^{2}$ seeding density. At $24 \mathrm{~h}$ from seeding, cells were incubated for $24 \mathrm{~h}$ with plain medium as control, $21.5 \mu \mathrm{M}$ Nut, $500 \mu \mathrm{g} / \mathrm{mL}$ PNPs, or $500 \mu \mathrm{g} / \mathrm{mL}$ Nut-PNPs for $24 \mathrm{~h}$. Thereafter, the culture inserts were removed, and the cells were washed with PBS and stained using $1 \mu \mathrm{M}$ calcein for $15 \mathrm{~min}$ at $37^{\circ} \mathrm{C}$ (Invitrogen). Cultures were stimulated with US as reported in section 2.12. The gap between the cells $(500 \mu \mathrm{m} \pm$ $100 \mu \mathrm{m}$ ) was imaged by using fluorescence microscopy (Eclipse Ti, Nikon) before starting the US stimulation protocol $(t=0 \mathrm{~h})$ and after the second stimulation session $(t=24 \mathrm{~h})$. The assay was performed in duplicate with three internal replicates, and at least three images were taken for each culture insert. The images were analyzed using Image software using the "Wound Healing" plug-in.

To estimate the relative amounts of cellular $f$-actin and $g$-actin, T98G cells were seeded in Culture Insert 2 Well systems (Ibidi), incubated with drug/nanoparticles and stimulated with US as described above. At the end of the treatment, cells were fixed with $4 \%$ PFA at $4^{\circ} \mathrm{C}$ for $20 \mathrm{~min}$ and permeabilized with $0.1 \%$ Triton X-100 (Sigma) for $15 \mathrm{~min}$. $f$-actin, $g$-actin and nuclei were labeled with TRITC-phalloidin $(1: 200)$, deoxyribonuclease I conjugate $\left(0.3 \mu \mathrm{M}\right.$, Invitrogen), and Hoechst $(1: 1000)$ at $37^{\circ} \mathrm{C}$ for 45 min, respectively. The images of the cells were acquired at the scratch region using confocal fluorescence microscopy. The $f-/ g$ actin signal ratio was finally analyzed with NIS-Elements software (Nikon).

Invasion of T98G cells (in the 8 experimental conditions) was assessed in vitro using the Cell Invasion Assay Kit (collagen I), 24-well, $8 \mu \mathrm{m}$ (Abcam) according to the manufacturer's protocol with some modifications. Briefly, the filter was coated using $100 \mu \mathrm{L}$ of collagen I to form a film. $200 \mu \mathrm{L}$ of a cell suspension (2.3.10 $\mathrm{T}$ T98G cells/chamber) in complete medium supplemented with drug or nanoparticles $(21.5 \mu \mathrm{M}$ Nut, $500 \mu \mathrm{g} / \mathrm{mL}$ PNPs, or 
$500 \mu \mathrm{g} / \mathrm{mL}$ Nut-PNPs) were added to each well of the upper chamber. $600 \mu \mathrm{L}$ of culture medium were placed in the lower chambers. After $12 \mathrm{~h}$ of incubation, lower chamber media were replaced with a control invasion-inducer medium $(1: 10, v / v)$, and the cultures were stimulated with US using the same parameters described above. Cells that did not undergo invasion on the upper chamber were removed by wiping with a cotton swab. Cell dye (1:250 dilution in PBS) was incubated for $30 \mathrm{~min}$ in the bottom chamber and, finally, the plate was read with a VICTOR X3 (PerkinElmer) plate reader $\left(\lambda_{\text {ex }} 485 \mathrm{~nm}, \lambda_{\text {em }} 530 \mathrm{~nm}\right.$ ). The fluorescence was then converted in cell number by using a standard curve.

\subsection{Proteomic analysis}

Samples from the 8 considered experimental classes and in experimental triplicate were lysed, reduced, and alkylated in $50 \mu \mathrm{L}$ LYSE buffer (Preomics) at $95^{\circ} \mathrm{C}$ for $10 \mathrm{~min}$, and sonicated with an Ultrasonic Processor UP200St (Hielscher) with 3 cycles of $30 \mathrm{~s}$. Lysed samples were digested with $0.7 \mu \mathrm{g}$ trypsin and $0.3 \mu \mathrm{g}$ LysC overnight at $37^{\circ} \mathrm{C}$. Thereafter, nanoparticles were separated from the samples centrifuging for $15 \mathrm{~min}$ at $18000 \mathrm{~g}$, and samples were treated with $30 \mu \mathrm{L}$ of $30 \%$ acetonitrile (ACN). The supernatant separated from the nanoparticles was concentrated, joined with the rest of the sample, and processed by iST protocol [51]. The resulting peptides were analyzed by a nano-UHPLC-MS/MS system using an Ultimate 3000 RSLC coupled to an Orbitrap Fusion Tribrid mass spectrometer (Thermo Scientific Instrument).

Elution was performed using a $200 \mathrm{~cm}$ uPAC C18 column (PharmaFluidics) mounted in the thermostated column compartment maintained at $50^{\circ} \mathrm{C}$. At first, a concentration gradient from 5 to $10 \%$ buffer B ( $80 \%$ ACN and $20 \% \mathrm{H}_{2} \mathrm{O}, 5 \%$ DMSO, 0.1\% FA) was applied, coupled with a flow gradient from $750 \mathrm{~nL} / \mathrm{min}$ to $350 \mathrm{~nL} / \mathrm{min}$ for $15 \mathrm{~min}$. Then, peptides were eluted with a 60 min linear gradient from 10 to $60 \%$ of buffer B at a constant flow rate of $350 \mathrm{~nL} / \mathrm{min}$. Orbitrap detection was used for MS1 measurements at a resolving power of $120 \mathrm{~K}$ in a range between 375 and $1500 \mathrm{~m} / \mathrm{z}$ and with a standard AGC target. Advanced peak detection was enabled for MS1 measurements. MS/MS spectra were acquired in the linear ion trap (rapid scan mode) after higher-energy C-trap dissociation (HCD) at a collision energy of $30 \%$ and with a Custom AGC target. For precursor selection, the least abundant signals in the three ranges $375-575 \mathrm{~m} / \mathrm{z}, 574-775 \mathrm{~m} / \mathrm{z}$ and $774-1500 \mathrm{~m} / \mathrm{z}$ were prioritized. Dynamic Exclusion was set at $25 \mathrm{~s}$.

MaxQuant software [52], version 1.6.17.0, was used to process the raw data. The false discovery rate (FDR) for the identification of proteins, peptides, and PSM (peptide-spectrum match) was set to 0.01 . A minimum length of 6 amino acids was required for peptide identification. Andromeda engine, incorporated into MaxQuant software, was used to search MS/MS spectra against Uniprot human database (release UP000005640_9606 October 2020). In the processing, the variable modifications were Acetyl (Protein NTerm), Oxidation (M) and Deamidation (NQ). Carbamidomethyl (C) was selected as a fixed modification. Algorithm MaxLFQ was chosen for the protein quantification with the activated option "match between runs" to reduce the number of the missing proteins. The intensity values were extracted and statistically evaluated using the ProteinGroup Table and Perseus software version 1.6.14.0 [53]. Perseus algorithm was used to perform principal component analysis (PCA) with default parameters. The PCA of the first 2 components for all the 3 experiments was plotted. GO enrichment specific for brain tissue was obtained with the webserver HumanBase [54].
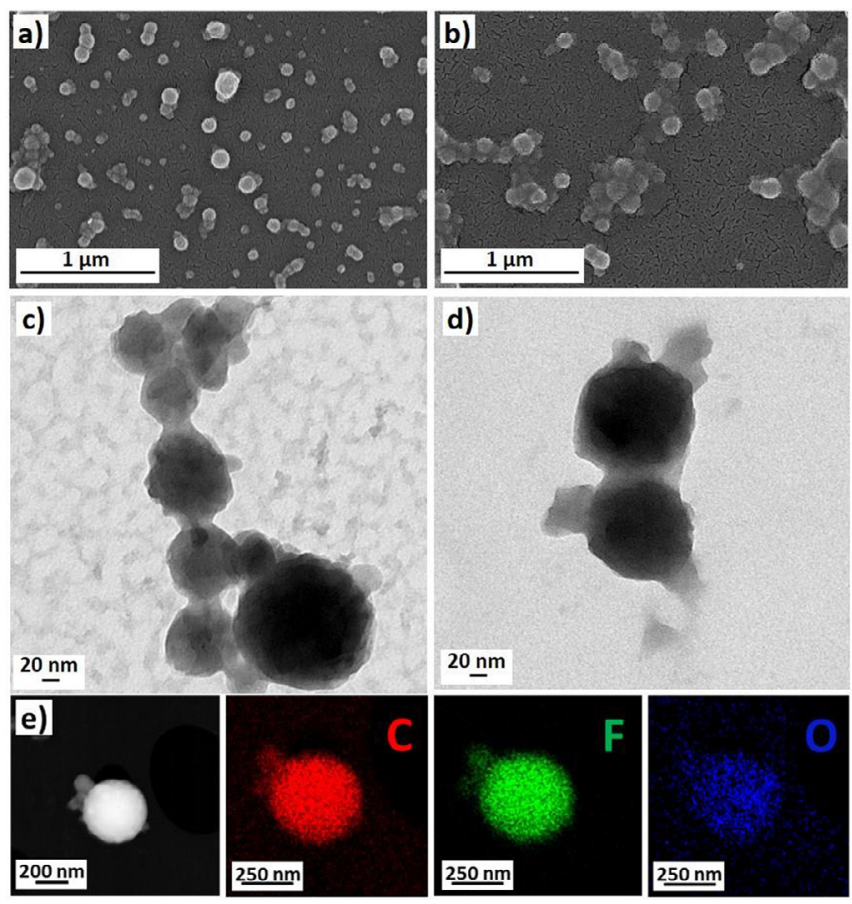

Fig. 1. Representative SEM images of a) plain and b) functionalized PNPs; representative TEM images of c) plain and d) functionalized PNPs; e) ADF/STEM image and elemental analysis (EDS) of PNPs for carbon (C, red), fluorine (F, green) and oxygen (O, blue).

\subsection{Statistical analysis}

Concerning BBB experiments, Student's t-test has been performed to compare the amount of functionalized vs. plain PNPs that crossed the barrier. In all other cases, ANOVA parametric test followed by Tukey's HSD post-hoc test was carried out for multiple distribution comparisons by using $R$ software (https://www. r-project.org/).

\section{Results and discussion}

\subsection{Physicochemical characterization of the nanoparticles}

DSPE-PEG-coated P(VDF-TrFE) nanoparticles (PNPs) were synthesized following a nanoprecipitation protocol adapted from Xiao et al [28], and functionalized with the peptide ApoE to favor the crossing of the blood-brain barrier [32].

SEM analysis shows the formation of spherical nanoparticles with a diameter of about $92 \pm 11 \mathrm{~nm}$ (Fig. 1a and Fig. S2a). The images also confirm that there is no significant increase in size after the functionalization of PNPs with ApoE $(115 \pm 20 \mathrm{~nm}$; Fig. $1 \mathrm{~b}$ and Fig. S2b). TEM analysis is in agreement with SEM imaging, showing particles with a mean diameter centered at around $89 \pm 10 \mathrm{~nm}$ before functionalization (Fig. 1c and Fig. S2c) and at $80 \pm 10 \mathrm{~nm}$ after functionalization (Fig. 1d and Fig. S2d). From the EDS analysis on plain PNPs (Fig. 1e and Fig. S3) it is possible to observe the presence of $\mathrm{C}$, due to the backbones of both the polymer and to the DSPE-PEG, F, due to P(VDF-TrFE), and O, stemming from the DSPEPEG. Notably, the co-localization of oxygen with carbon and fluoride confirms the successful coating of the P(VDF-TrFE) core with lipid molecules. To the best of our knowledge, this is the first example of hybrid lipid-polymeric nanoparticles prepared from the piezoelectric polymer $\mathrm{P}(\mathrm{VDF}-\mathrm{TrFE})$. The addition of the lipid layer on the polymeric core is extremely important for biological applications, since it ensures higher biocompatibility, stealth stabil- 
ity, and makes easier further functionalization with specific ligands [29].

The size of PNPs was also measured by dynamic light scattering (Fig. 2a). The intensity distribution shows a fairly monodisperse population with an average hydrodynamic diameter of $203 \pm 3$ $\mathrm{nm}$, a polydispersity index (PdI) of $0.17 \pm 0.03$ and a $\zeta$-potential of $-20 \pm 1 \mathrm{mV}$ (Fig. 2b). The functionalization with ApoE does not significantly affect the size, the PdI, and the $\zeta$-potential of the nanoparticles $(251 \pm 20 \mathrm{~nm}, 0.19 \pm 0.02$, and $-18.1 \pm 0.3 \mathrm{mV})$.

The crystalline phases of $\mathrm{P}(\mathrm{VDF}-\mathrm{TrFE})$ confined in the core of PNPs were investigated by FTIR and Raman spectroscopy (Fig. 2cd). Both bulk P(VDF-TrFE) and PNPs FTIR spectra present the peculiar peaks at 842 and $1279 \mathrm{~cm}^{-1}$, corresponding to the $\beta$-phase of the polymer. The typical peaks of the $\alpha$-phase arrangement (610, $765,965 \mathrm{~cm}^{-1}$ ) are very weak and extremely difficult to identify, especially for PNPs (Fig. 2c) [38]. This suggests that the polymer preferentially crystallizes in the $\beta$-phase. From the absorbance of the peaks at 765 ( $\alpha$-phase) and $842 \mathrm{~cm}^{-1}$ ( $\beta$-phase), it is possible to determine the fraction $F(\beta)$ of $\mathrm{P}(\mathrm{VDF}-\mathrm{TrFE})$ in the $\beta$-phase (see in the "Materials and Methods" section). The analysis of FTIR spectra in Fig. $2 c$ indicates that $F(\beta)$ in the bulk polymer is around 0.7 , whereas PNPs undergone the reflux procedure increases $F(\beta)$ up to 1.0 , in agreement with the poor intensity of all the $\alpha$-phase-related peaks in the FTIR spectra.

Raman spectroscopy (Fig. 2d) also gives useful information regarding the crystalline conformation of $\mathrm{P}(\mathrm{VDF}-\mathrm{TrFE})$ in the nanoparticles. In fact, the $\alpha$-phase has a characteristic peak at around $803 \mathrm{~cm}^{-1}$, whereas the $\beta$-phase gives a peak at $848 \mathrm{~cm}^{-1}$. Also in this case, from the intensities of these two contributions, it is possible to estimate the ratio between the $\beta$ - and $\alpha$-phase in the sample [38]. In agreement with FTIR, Raman spectroscopy highlights a significant increase of the $\beta$-phase in PNPs $(\beta / \alpha=3)$, as compared to $\mathrm{P}(\mathrm{VDF}-\mathrm{TrFE})$ powder $(\beta / \alpha=2)$. These results confirm that the PNPs preparation protocol ensures successful recrystallization of the polymer predominantly in the $\beta$-phase, which is the most interesting phase when looking for optimal piezoelectric and ferroelectric properties [55].

As reported in literature, pure PVDF can crystallize in four different phases: $\alpha, \beta, \delta$, and $\gamma$, but it mainly assumes the nonpolar $\alpha$-phase when recrystallized from its melt [55-57]. In order to obtain the $\beta$-phase, PVDF needs to be mechanically stretched or poled $[58,59]$. The addition of TrFE to form the copolymer P(VDFTrFE) is known to spontaneously favor the orientation in the $\beta$ phase [24]. This is in agreement with the high $\beta$-fraction observed in the bulk $\mathrm{P}(\mathrm{VDF}-\mathrm{TrFE})$ used in this work, with a TrFE content equal to $45 \%$. Nonetheless, as already reported by Xiao et al., the nanoparticle formulation protocol and, in particular, the reflux procedure, are able to further increase the content of the $\beta$-phase, improving the piezoelectric properties of the polymer [28].

TGA analysis (Fig. 2e) shows the typical degradation temperatures of the components of plain PNPs. Bulk P(VDF-TrFE) has a distinct degradation temperature at $475^{\circ} \mathrm{C}$, whereas DSPE-PEG at $380^{\circ} \mathrm{C}$. In plain PNPs (Fig. 2e and Fig. S4, blue curve), the contributions of the two materials are still distinguishable, allowing to estimate that PNPs are composed of around 30\% w/w of DSPE-PEG and $70 \% \mathrm{w} / \mathrm{w}$ of $\mathrm{P}(\mathrm{VDF}-\mathrm{TrFE})$.

DSC thermograms of bulk P(VDF-TrFE), DSPE-PEG, and plain PNPs are reported in Fig. 2f. P(VDF-TrFE) (black line) thermogram shows the typical endothermic peak at $73^{\circ} \mathrm{C}$ corresponding to the transition from the ferroelectric to the paraelectric phase (Curie temperature, $T_{C}$ ) [60]. At higher temperatures, another endothermic peak $\left(156^{\circ} \mathrm{C}\right)$ due to the polymer fusion $\left(T_{m \text {,polymer }}\right)$ can be observed; the associated enthalpy of fusion is equal to $-25 \mathrm{~J} / \mathrm{g}$, in agreement with the values reported in the literature [55]. Pure DSPE-PEG presents an endothermic peak (melting, $T_{m, l i p i d}$ ) at $59^{\circ} \mathrm{C}$, mainly due to the PEG contribution, with a small shoulder at lower temperatures (around $54^{\circ} \mathrm{C}$ ), due to DSPE; the overall enthalpy of fusion is $-101 \mathrm{~J} / \mathrm{g}$ [61]. In plain PNPs (blue curve), all the peaks of the individual components are still evident, with no significant shifts in the temperatures of the specific thermal events. However, the enthalpy of fusion associated with DSPE-PEG is lower in PNPs $(-76 \mathrm{~J} / \mathrm{g})$, indicating a more disordered arrangement of the lipid when forming the coating around PNPs. On the other hand, the enthalpy of fusion associated with P(VDF-TrFE) is higher (-35 $\mathrm{J} / \mathrm{g}$ ), suggesting a higher crystallinity of the polymer after the PNPs preparation procedure.

The stability of PNPs, in terms of hydrodynamic diameter and polydispersity index, has been evaluated in different conditions (Fig. 2g-h): $\mathrm{H}_{2} \mathrm{O}$, PBS, PBS $+\mathrm{H}_{2} \mathrm{O}_{2}(100 \mu \mathrm{M}), \mathrm{pH} 4.5$, pH $4.5+\mathrm{H}_{2} \mathrm{O}_{2}$ $(100 \mu \mathrm{M})$, DMEM + FBS $(10 \%)$ and DMEM + FBS $(10 \%)+\mathrm{H}_{2} \mathrm{O}_{2}$. The average hydrodynamic diameter of PNPs is stable in $\mathrm{H}_{2} \mathrm{O}$, PBS and PBS $+\mathrm{H}_{2} \mathrm{O}_{2}(100 \mu \mathrm{M})$ for at least 7 weeks after the preparation. In DMEM + FBS and DMEM + FBS $+\mathrm{H}_{2} \mathrm{O}_{2}$ the hydrodynamic diameter increases from $221 \pm 9 \mathrm{~nm}$ and $218 \pm 5 \mathrm{~nm}$ to $349 \pm 21$ and $388 \pm 15 \mathrm{~nm}$, respectively, after 7 weeks; a slight increase is noticeable already after 3 weeks, probably due to the formation of a protein corona around the nanoparticles that screens surface charges, reducing electrostatic repulsion and, thus, facilitating aggregation phenomena. This increment in size corresponds to an increment of the PdI (Fig. 2h) as well. Again at pH 4.5 (either with or without $\mathrm{H}_{2} \mathrm{O}_{2}$ ), PNPs start to form larger and more polydisperse aggregates after 3 weeks from their preparation. SEM analysis (Fig. S5) corroborates dynamic light scattering measurements, even though no evident degradation of the nanoparticles could be detected in these conditions.

The successful functionalization of PNPs with the peptide ApoE was first tested with SDS-PAGE. As shown in Fig. 3a, functionalized PNPs give rise to a band corresponding to the peptide, similarly to ApoE alone. The specificity of the method is confirmed by the absence of any detectable signal in PNPs. Comparing the intensity of the band of PNPs with that one of the peptide alone, it was estimated that ApoE accounts for the $1.6 \pm 2 \mathrm{wt} \%$ of the nanoparticles. Fluorescence spectroscopy has been used to confirm the presence ApoE, by exploiting its fluorescence similarly to what already done in previous reports $[32,39]$. PNPs and the peptide alone show a typical fluorescence emission at $350 \mathrm{~nm}$; on the other hand, plain PNPs do not show appreciable fluorescence (Fig. 3b). By comparing the emission intensity of functionalized PNPs to a calibration curve obtained with different concentrations of the free peptide, the wt\% of the peptide bound to the surface of the nanoparticles was found to be $1.7 \pm 0.5$. Finally, the functionalization was also quantified to be $1.1 \pm 0.7$ wt\% with the BCA assay. The amounts of ApoE in PNPs determined with these different techniques are in quite good agreement; considering the nanoparticle size (from SEM and TEM analysis), the density of ApoE molecules on PNPs surface was found to be $0.2-0.1$ peptide $/ \mathrm{nm}^{2}$, in agreement with values found in the literature $[39,62]$.

Nutlin-3a loading in PNPs was evaluated by HPLC to be $2.5 \pm$ $0.7 \mathrm{wt} \%$. The release of nutlin-3a from the nanoparticles was studied at the same temporal and US stimulation protocol used to treat the cells and in different buffers: at pH 4.5 and 7.4, with or without US stimulation. From Fig. 4a-b, it is evident that the highest cumulative release of the drug is obtained at $\mathrm{pH} 4.5$ plus the ultrasound stimulation ( $12.5 \pm 0.3 \%$ of release after $48 \mathrm{~h}$ ). A more efficient release of nutlin-3a in acidic conditions has been already observed in a previous study, and it is probably due to a higher solubility of the drug in these conditions [39].

Moreover, the stability studies showed that PNPs are less stable at $\mathrm{pH} 4.5$, favoring thus the release of encapsulated substances. At both $\mathrm{pH} 7.4$ and 4.5, US slightly increases the release of nutlin$3 a$, most likely due to mechanical stress and/or to polarizationdepolarization effects in the piezoelectric polymeric core [24]. 
a)

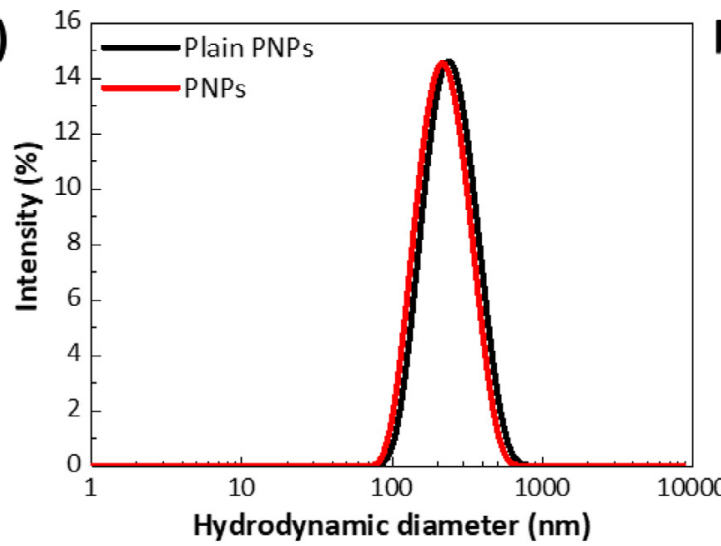

c)

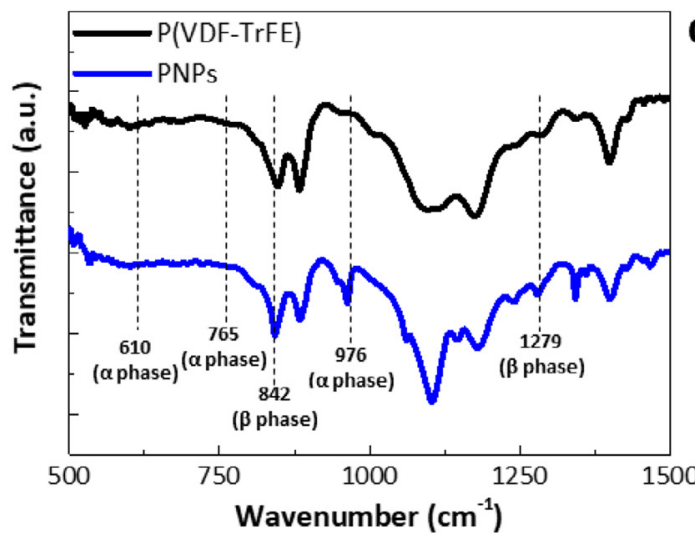

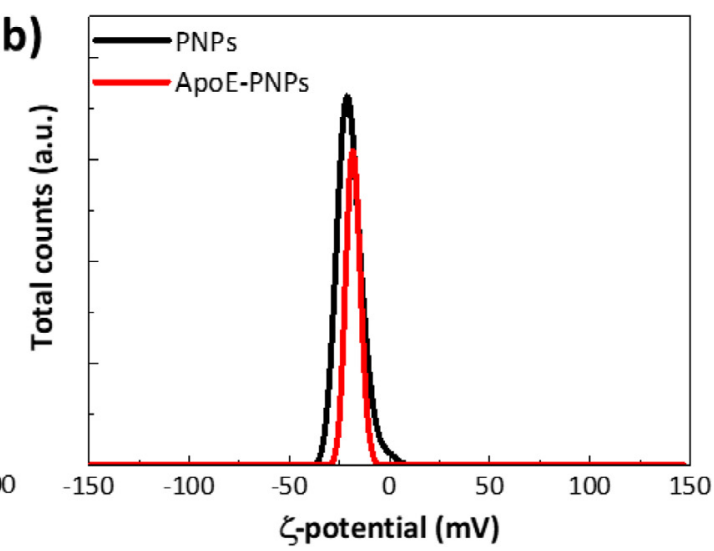

d)

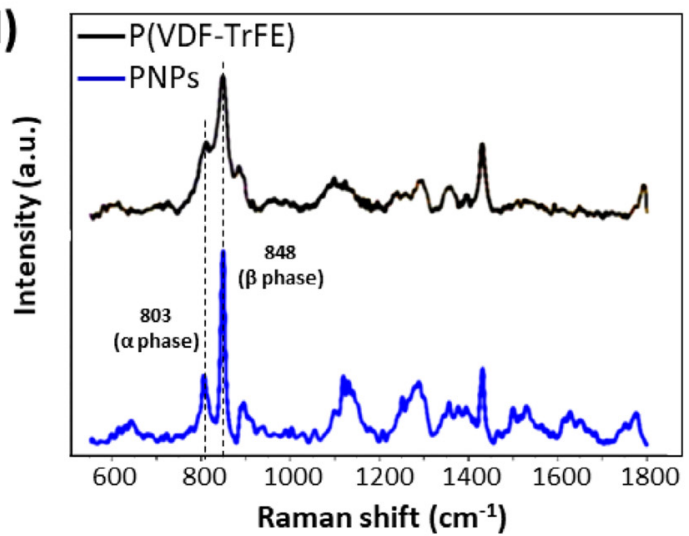

e)

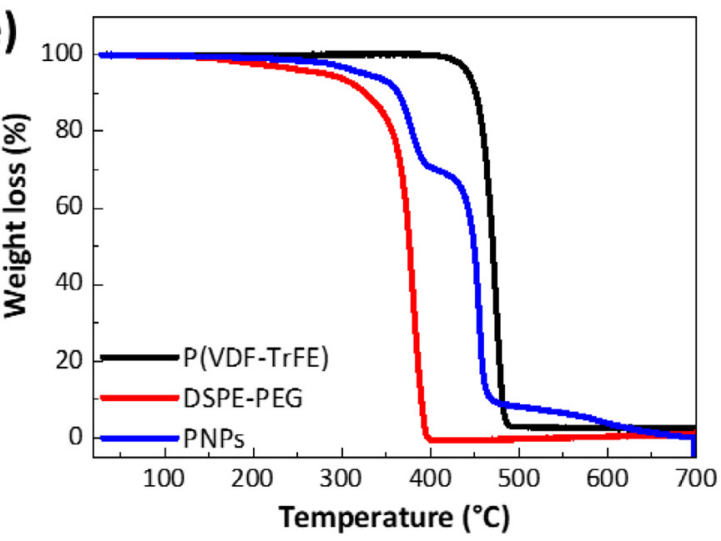

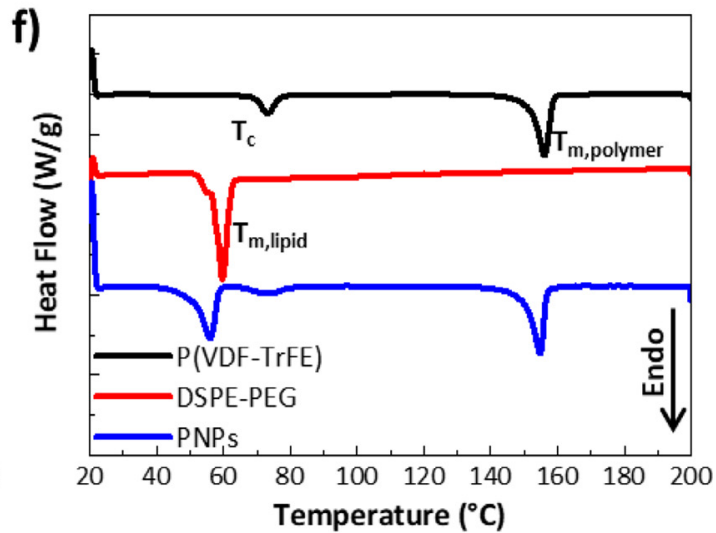
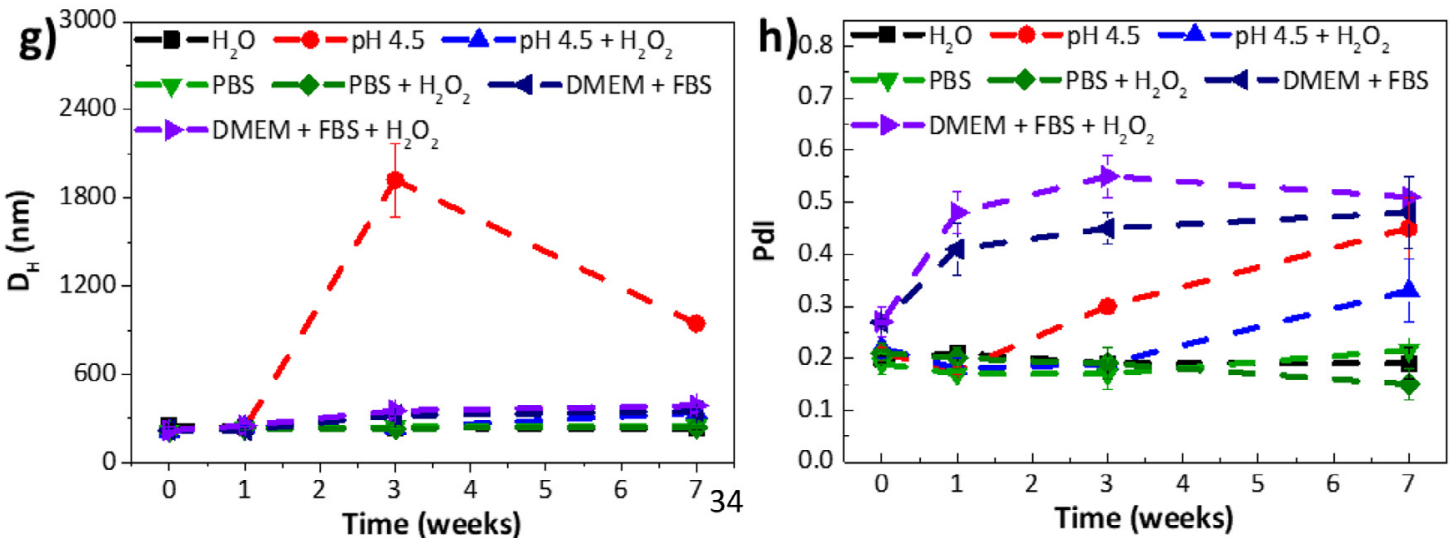

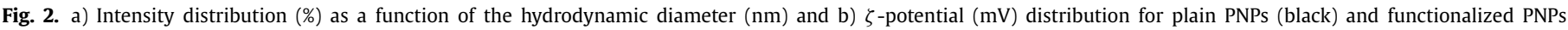

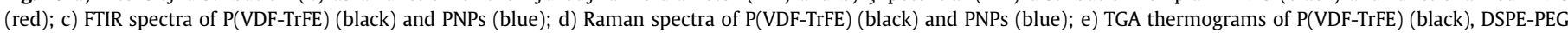

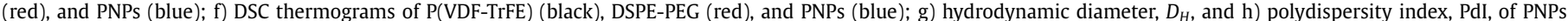

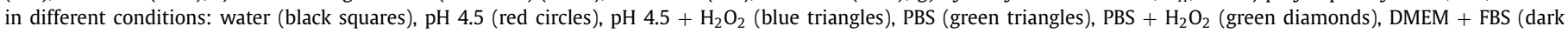
blue triangles), and DMEM $+\mathrm{FBS}+\mathrm{H}_{2} \mathrm{O}_{2}$ (violet triangles). 
a)

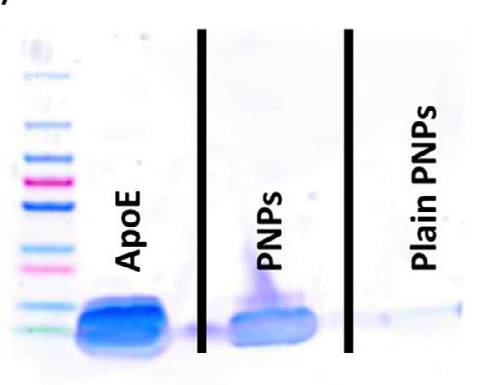

b)

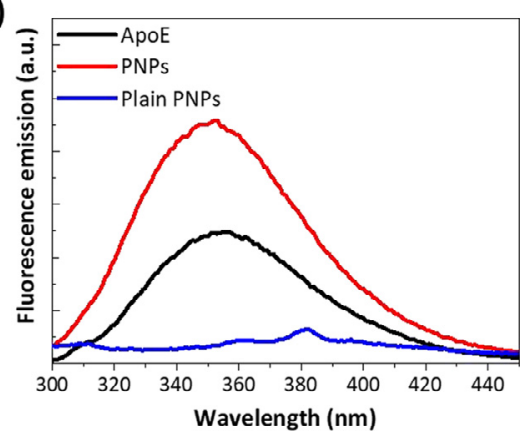

Fig. 3. a) SDS-PAGE of ApoE, functionalized PNPs, and plain PNPs; b) fluorescence spectroscopy of ApoE (black), functionalized PNPs (red), and plain PNPs (blue).

a)

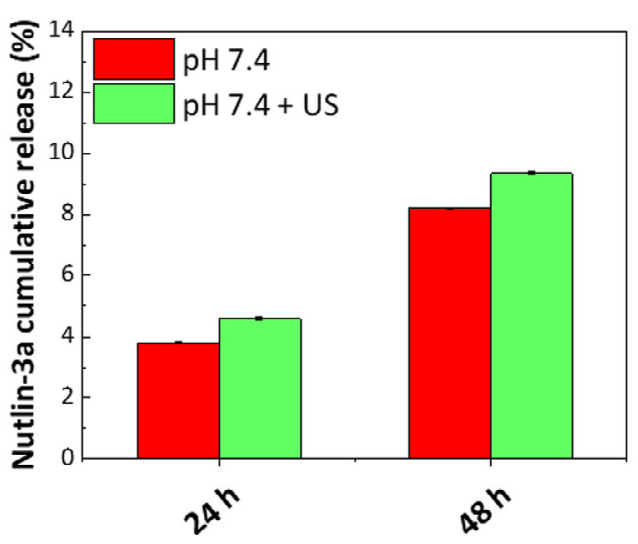

b)

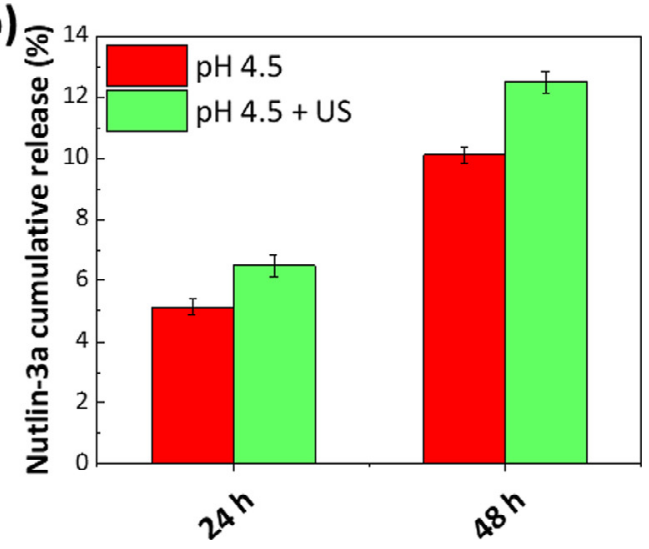

Fig. 4. Nutlin-3a cumulative release (\%) from Nut-PNPs at a) $\mathrm{pH} 7.4$ and b) $\mathrm{pH} 4.5$, without (red) and with (green) US stimulus.

These results suggest that PNPs could be more prone to releasing their cargo in cancer cells, that are known to possess a more acidic internal $\mathrm{pH}$ as compared to healthy cells, or in acidic intracellular organelles, such as lysosomes, and, more interestingly, that the release can be favored by applying an US stimulus.

Despite this rather low drug release from the nanoparticles, we have to consider thet release studies provide a general overview of the release behavior of the drug, without taking into account the complex interactions and degradation processes that occur within cells (e.g., enzymes might foster the degradation of nanoparticles with consequent release of the drug in the intracellular environment).

To study the ability of plain and functionalized PNPs to cross the BBB, an ad hoc fluidic system has been used to recreate the flow conditions that brain capillaries usually experience in vivo (Fig. S1) $[39,40]$. The BBB model was obtained by co-culturing human endothelial cells (hCMEC/D3) and human brain-derived astrocytes (HA) on a porous membrane (as described in the "Materials and Methods" section). It has been previously shown that the presence of both the flow and the astrocytes confers to the endothelial cell cultures the typical BBB phenotype (the formation of tight junction and the expression of specific proteins, for instance) [63,64].

The BBB model showed a TEER of $267 \pm 33 \Omega \cdot \mathrm{cm}^{2}$, and its $P_{a p p}$ and $P_{e}$ to rhodamine B-dextran $(70 \mathrm{kDa})$ were around $1.1 \cdot 10^{-6}$ $\pm 0.2 \cdot 10^{-6} \mathrm{~cm} / \mathrm{s}$ and $1.3 \cdot 10^{-6} \pm 0.4 \cdot 10^{-6} \mathrm{~cm} / \mathrm{s}$, respectively, in agreement with other similar BBB models (Fig. S6) [65,66]. Fig. 5ab show confocal images of the BBB after interaction with either plain or functionalized PNPs. In both cases, a tight monolayer of hCMEC/D3 cells can be observed. Just a few amounts of nanopar- ticles are present on the $\mathrm{BBB}$, and in particular, in peripheral position with respect to both hCMEC/D3 and HA. This suggests that, after interacting with the cells of the BBB, nanoparticles are not retained, but rather excreted to the other side via transcytosis mechanisms during the perfusion. In particular, it has been previously shown that apolipoprotein $\mathrm{E}$ amino acids interact with low-density lipoprotein receptors on the endothelial cells favoring transcytosis, thus avoiding undesired effects caused by lysosomal degradation $[33,67]$. We, therefore, expect that transcytosis might be the preferred pathway, especially for functionalized PNPs.

Quantitatively, after $48 \mathrm{~h}$ from the crossing experiment, the amount of plain PNPs in the lower chamber was $43 \pm 1 \mu \mathrm{g}$; conversely, the amount of functionalized PNPs was around $55 \pm 1 \mu \mathrm{g}$, corresponding to an increment of about $20 \%$ of nanoparticles that crossed the BBB ( $p<0.05$; $t$-test), confirming the active role of the ApoE peptide in promoting BBB passage.

\subsection{Drug and nanoparticle testing in glioblastoma cell lines}

The effect of the chemotherapy drug $(0.2,1.0,5.0$, and $25.0 \mu \mathrm{M})$ has been tested on different glioblastoma cell lines (T98G, U251, and U87 MG; Fig. S7). T98G cell culture viability was not affected by Nut even when cells were treated with the highest drug concentration (Fig. S7a; $p>0.05$ ). In U251 cells, a significant decrease of cell viability was observed for $0.2 \mu \mathrm{M}$ (15.2\% decrease), $1.0 \mu \mathrm{M}$ (19.6\% decrease), $5.0 \mu \mathrm{M}$ (27.6\% decrease), and $25.0 \mu \mathrm{M}(47.7 \%$ decrease) Nut concentrations, showing a concentration-dependent sensitivity of these cells to the chemotherapy treatment (Fig. S7b; $p<0.05)$. U87 MG cell viability was also significantly affected at $1.0 \mu \mathrm{M}$ (40.0\% decrease), $5.0 \mu \mathrm{M}(62.9 \%$ decrease $)$, and $25.0 \mu \mathrm{M}$ 

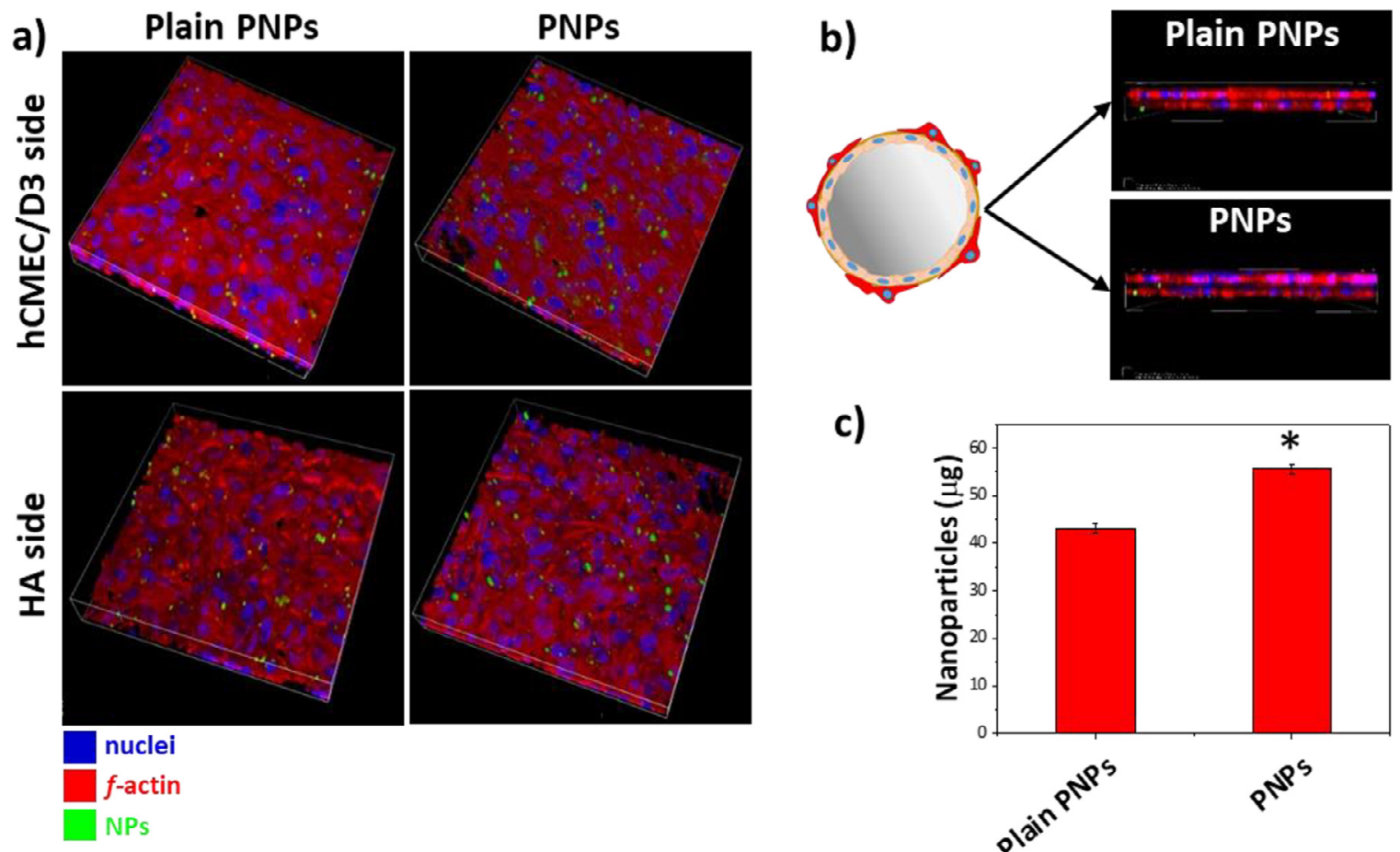

c)

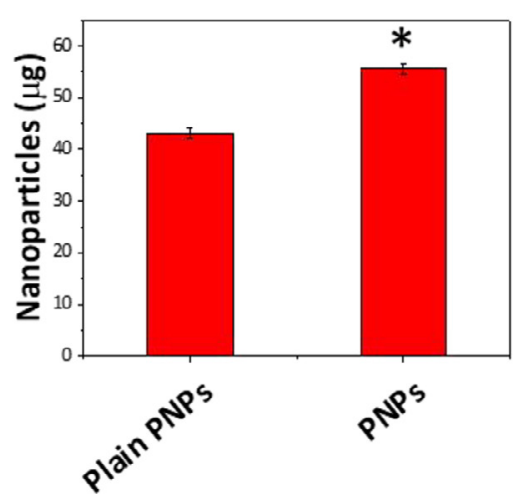

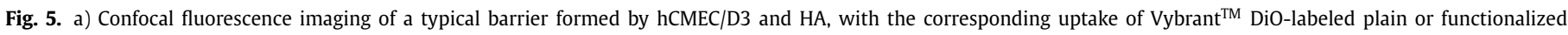

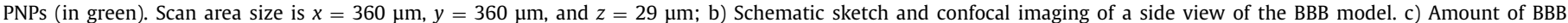
crossed nanoparticles (in $\mu \mathrm{g})$ at $48 \mathrm{~h}\left({ }^{*} \mathrm{p}<0.05\right)$.

Nut (75.4\% decrease; Fig. S7c; $p<0.05)$. These results showed as T98G cultures were resistant to drug treatment even when treating cells with $25 \mu \mathrm{M}$ Nut, a concentration 5 times higher with respect to that one found to be toxic towards the other glioblastoma cell lines. The resistance of T98G cells to Nut treatment in this concentration range is in line with observations previously reported in the literature [68].

The toxicity of PNPs and of Nut-loaded PNPs (Nut-PNPs) was assessed by WST-1 assay (Fig. 6). Concerning PNPs (Fig. 6a), no significant effect on cell culture metabolism was observed in cultures treated with $100,250,500$, or $1000 \mu \mathrm{g} / \mathrm{mL}$ PNPs in the 3 glioblastoma cell lines, demonstrating optimal biocompatibility of the nanomaterial (Fig. 6a; $p>0.05$ ). Instead, Nut-PNPs significantly affected the viability of U251, T98G and U87 MG cells (Fig. 6b). Specifically, U251 cells treated with 250,500 , or $1000 \mu \mathrm{g} / \mathrm{mL}$ NutPNPs showed significantly decreased viability $(76.9 \pm 2.8 \%$ for 250 $\mu \mathrm{g} / \mathrm{mL}, 79.1 \pm 2.8 \%$ for $500 \mu \mathrm{g} / \mathrm{mL}$, and $80.5 \pm 2.8 \%$ for $1000 \mu \mathrm{g} / \mathrm{mL}$ Nut-PNPs) with respect to controls $(100.0 \pm 3.8 \%$; $p<0.05)$. Concerning T98G cells, a significant decrease of viability was found for both $500 \mu \mathrm{g} / \mathrm{mL}(81.9 \pm 3.4 \%)$ and $1000 \mu \mathrm{g} / \mathrm{mL}$ Nut-PNPs $(63.4 \pm$ $2.5 \%)$ with respect to controls $(100.0 \pm 2.9 \% ; p<0.05)$. A significant decrease of the U87 MG culture viability was observed in response to the treatments with $500(57.7 \pm 7.7 \%)$, and $1000(32.0 \pm$ $3.0 \%) \mu \mathrm{g} / \mathrm{mL}$ Nut-PNPs with respect to controls $(100.0 \pm 2.1 \% ; p<$ $0.05)$. Considering that Nut represents $2.5 \mathrm{wt} \%$ of Nut-PNPs, Nut concentrations corresponding to $100,250,500$, and $1000 \mu \mathrm{g} / \mathrm{mL}$ Nut-PNPs were respectively $4.3,10.8,21.5$, and $43.0 \mu \mathrm{M}$. Interestingly, despite T98G cultures were not sensitive to $25 \mu \mathrm{M}$ Nut, Nut sensitivity was instead observed in these cells when treated with $500 \mu \mathrm{g} / \mathrm{mL}$ Nut-PNPs, corresponding to $21.5 \mu \mathrm{M}$ Nut. The sensitivity of all the investigated glioblastoma cell lines to Nut-PNPs was considered of great interest for the treatment of GBM cells with different molecular genotypes. The following experiments have been designed to investigate nanoparticle internalization, drug effects and piezoelectric stimulation in the Nut resistant T98G cells by using $500 \mu \mathrm{g} / \mathrm{mL}$ of nanoparticles.

\subsection{Cell/nanoparticle interaction}

Cellular localization of PNPs in T98G cells was qualitatively assessed at 24 and $72 \mathrm{~h}$ of incubation. Fig. 7 shows confocal fluorescence microscopy imaging of nuclei (blue), fluorescently-labeled PNPs (green), and $f$-actin (red). The $f$-actin staining has been used in Fig. 7 as a non-specific cell marker to evaluate the nanoparticle internalization. In these images, the cortical $f$-actin also allows the identification of the edges of single cells. In Fig. 7a and 7b, a single $z$-stack and the 3D confocal reconstruction of the cells during nanoparticle internalization are shown, respectively. The particles were observed in the perinuclear area, and an increase of PNPs signal was detected at $72 \mathrm{~h}$ of particle incubation with respect to $24 \mathrm{~h}$ of incubation. The progressive and slow internalization rate of the nanoparticles and can be attributed to the negative $\zeta$-potential of the nanoparticles, that is indeed associated with a decreased cytotoxicity [69].

Confocal Raman microscopy imaging was exploited to analyze the internalization of label-free PNPs in T98G cells (Fig. 8). Fig. 8a shows the signals originating from PNPs (in red the $\beta$-phase of the PNPs: $\beta$-phase: $820 \mathrm{~cm}^{-1}>$ Raman shift $>880 \mathrm{~cm}^{-1}$ ), from cell proteins (in green the amide I region: $1600 \mathrm{~cm}^{-1}>$ Raman shift $>$ $1700 \mathrm{~cm}^{-} 1$ ), the bright field (Bf), and the merged images (Merge). Arrows indicate the cell regions with nanoparticles (overlap of the red and green signals in yellow). In Fig. 8b, representative Raman spectra of PNPs outside the cells (PNPs), of cell regions without nanoparticles (Cell), and of cell regions with PNPs (PNPs in cell) are reported. To investigate the possible presence of nanoparticles in cell nuclei, high-resolution confocal Raman microscopy imaging of PNPs (in red the $\beta$-phase of the PNPs: $\beta$-phase: $820 \mathrm{~cm}^{-1}>$ Raman shift $>880 \mathrm{~cm}^{-1}$ ) and of nuclei (DNA in blue: $760 \mathrm{~cm}^{-1}$ $>$ Raman shift $>790 \mathrm{~cm}^{-1}$ ) was performed (Fig. 8c). The signal of 


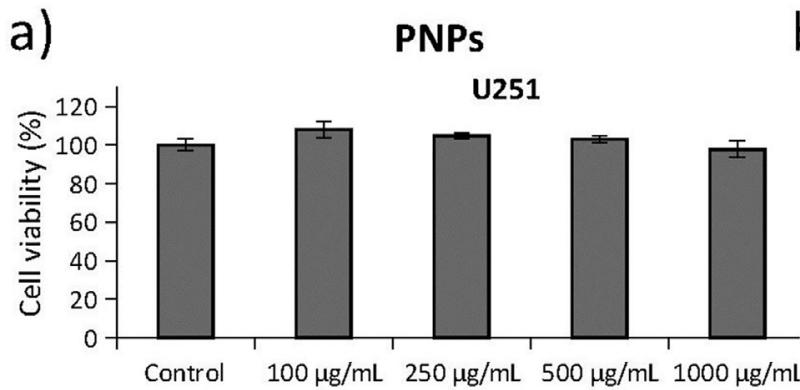

b) Nut-PNPs
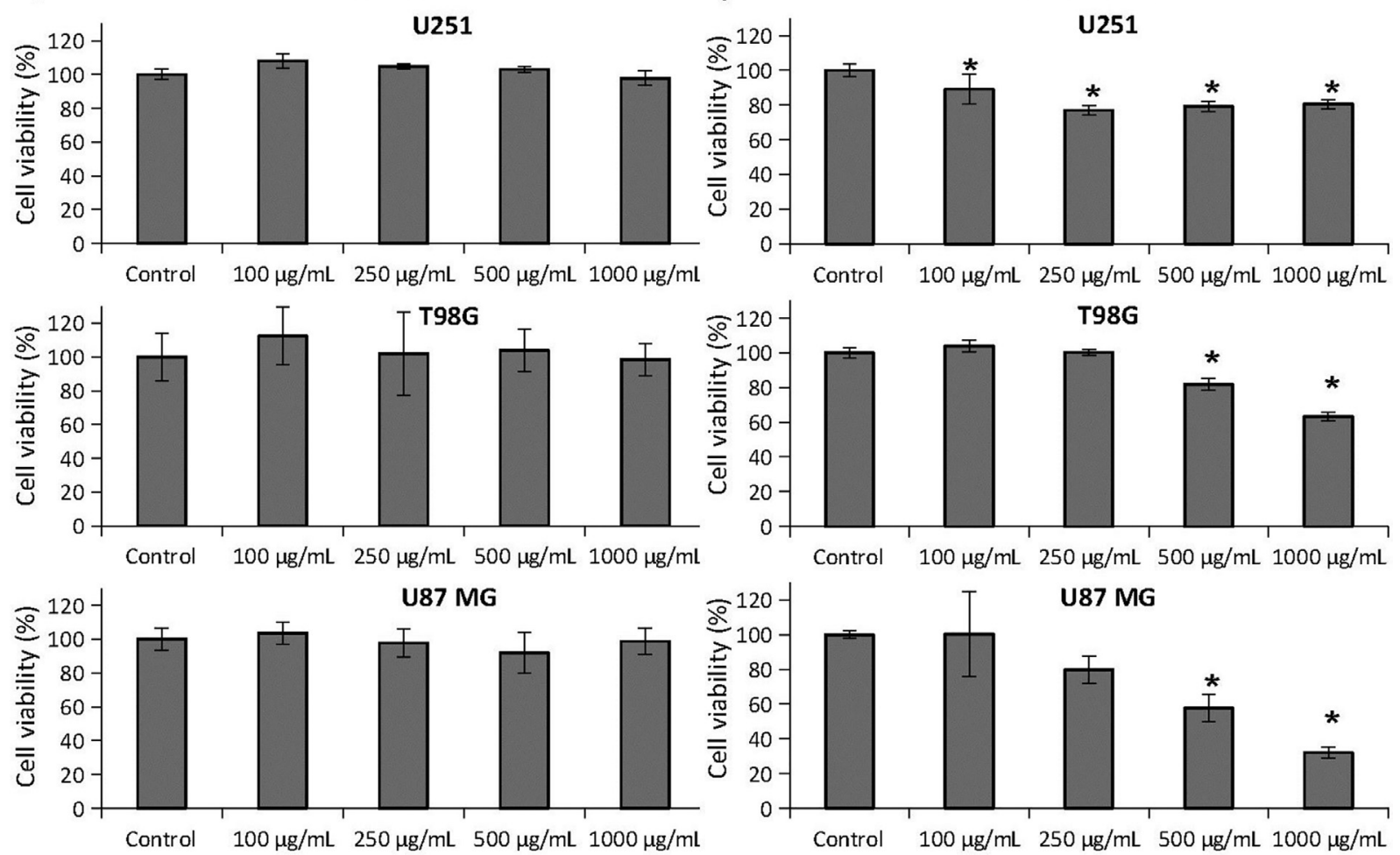

Fig. 6. Investigation of the toxicity of a) PNPs and b) Nut-loaded PNPs (Nut-PNPs) in U251, T98G, and U87 MG cell lines by using WST- 1 cell viability assay. ${ }^{*} p<0.05$.
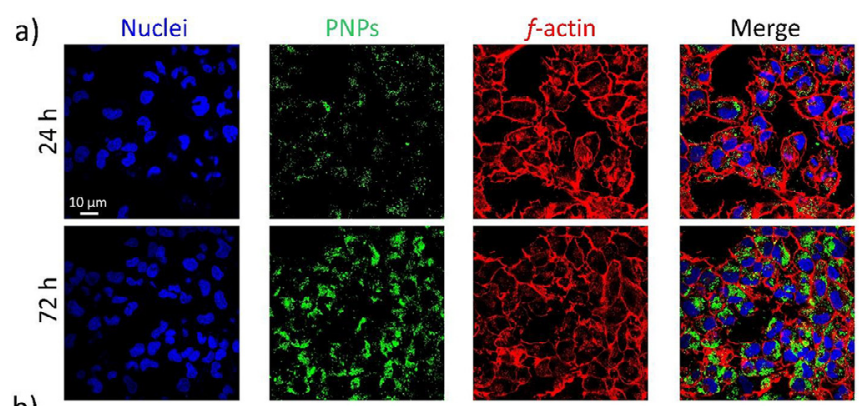

b)

Nuclei
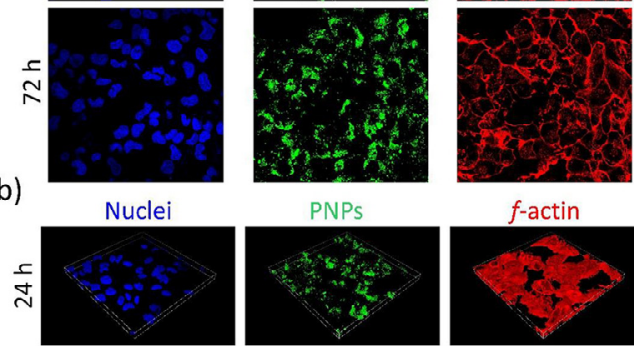

$f$-actin
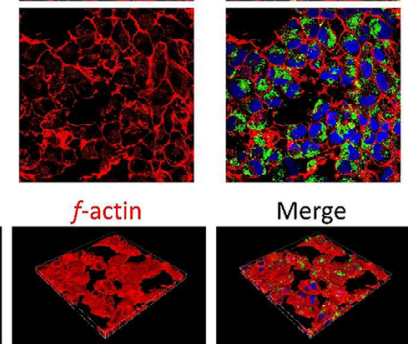

Merge
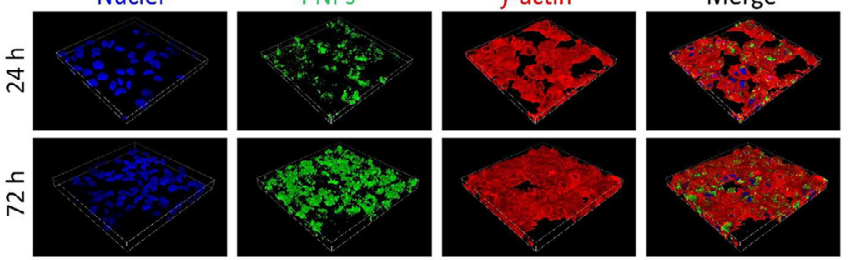

Fig. 7. Internalization of fluorescently-labeled PNPs in T98G cells at 24 and $72 \mathrm{~h}$ of incubation. Confocal fluorescence microscopy imaging of nuclei (blue), DiO-stained PNPs (green) and $f$-actin (red). a) Representative single $z$-stack image and b) 3D confocal reconstruction of the cells during nanoparticle internalization.

the PNPs is perinuclear and the imaging shows no co-localization with the signal of the nuclei; representative Raman spectra of the nucleus and of the PNPs on the nucleus are shown in Fig. 8d.. Altogether, these observations confirm label-free PNP uptake by T98G cells with undetectable internalization in cell nuclei.

\subsection{Piezoelectric cancer cell stimulation, apoptosis and necrosis}

Low-intensity electromagnetic fields are known to induce intracellular $\mathrm{Ca}^{2+}$ increments and to reduce cell proliferation [70]; analogous phenomena have been also observed in breast and GBM cells in response to chronic piezoelectric stimulations by exploiting inorganic $\mathrm{BaTiO}_{3}$ NPs activated by US $[15,20]$. In this work, we investigated for the first time the ability of US-activated organic piezoelectric PNPs to trigger $\mathrm{Ca}^{2+}$ fluxes in glioblastoma cells, and we analyzed the effects of the chronic piezoelectric stimulation on cell necrosis and apoptosis.

In Fig. 9, $\mathrm{Ca}^{2+}$ imaging of cultures previously incubated with PNPs and stimulated with US (PNPs + US) is shown. Results have been compared with control cultures non-incubated with PNPs and stimulated with US (US). Time-lapse $F / F_{0}$ images of $\mathrm{Ca}^{2+}$ signal just before ( $8 \mathrm{~min})$ and during (33, 60 and $85 \mathrm{~min}$ ) the US stimulation are reported in Fig. 9a. The $F / F_{0}$ traces of US-stimulated cells without (in black) and with (in red) PNP pre-incubation are shown in Fig. 9b (the black line at the top of the graph indicates the period of the chronic US stimulation starting at $t=500 \mathrm{~s}$ ). An increase of the $\mathrm{Ca}^{2+}$ signal was found just in PNPs + US cultures, indicating that the adopted stimulation protocol was able to induce cellular activation in terms of $\mathrm{Ca}^{2+}$ levels only in the presence of the piezoelectric nanotransducers. The sustained high levels of intracellular $\mathrm{Ca}^{2+}$ are associated with the chronic pulsed treatment, which consisted in repeated US stimulations (stimuli activated every $2 \mathrm{~s}$ that lasted $200 \mathrm{~ms}$ each). Such long-duration $\mathrm{Ca}^{2+}$ waves can be also induced in cancer cells by chronic electrical stimulations [70]. To our knowledge, this is the first direct demonstration of cell activation assisted by organic piezoelectric nanoparticles, and these findings are in line with previous results obtained with inorganic piezoelectric nanoparticles activated with the same stimulation protocol [15].

The effects of chronic piezoelectric stimulation combined with the Nut chemotherapy drug in terms of apoptosis and necrosis was investigated in T98G cells by considering 8 experimental groups (Fig. 10): controls without (Control) or with (Control + US) US stimulation, cells incubated with free Nut without (Nut) or with 
a)
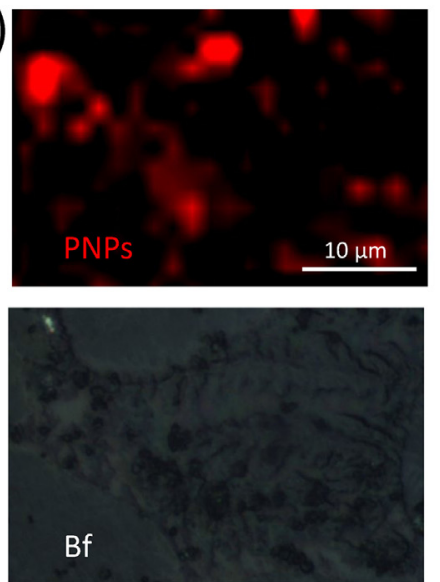

c)
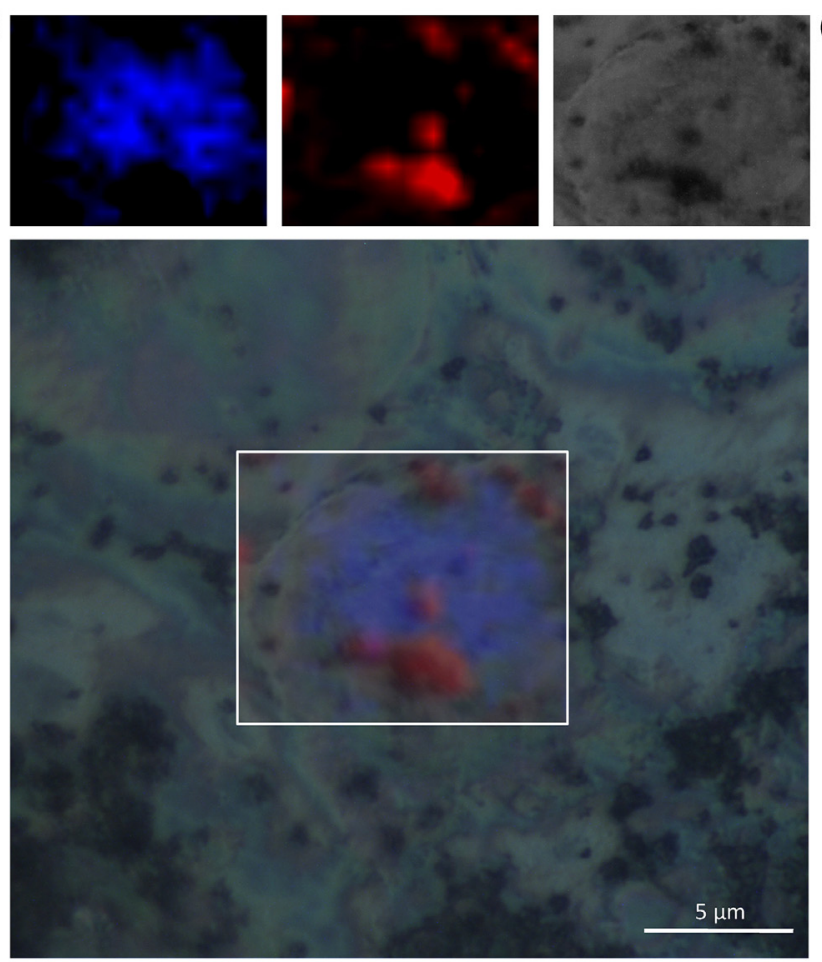
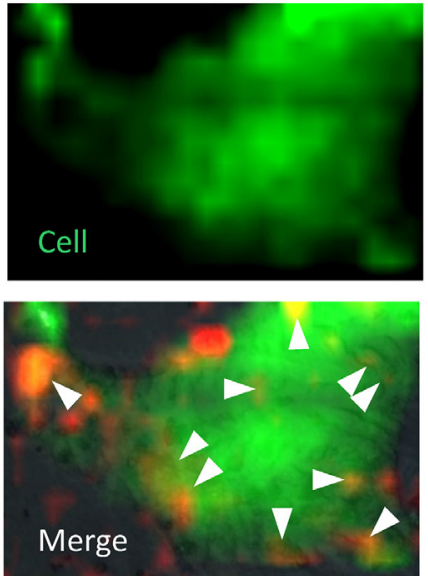

d)
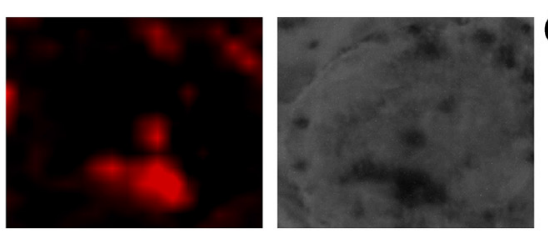

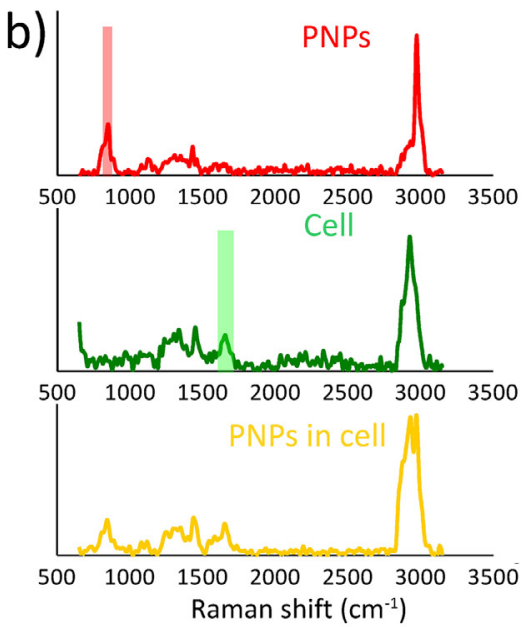

DNA in nucleus
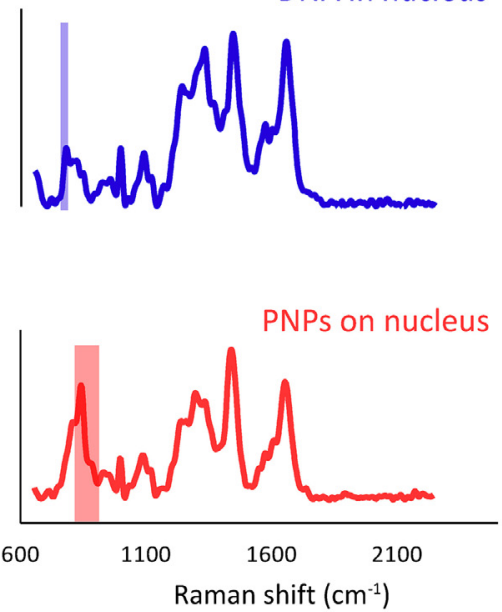

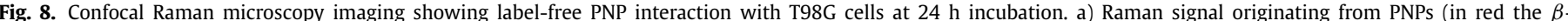

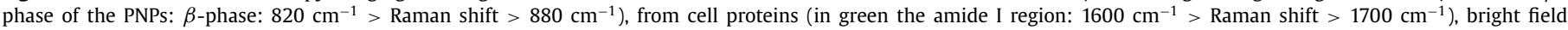

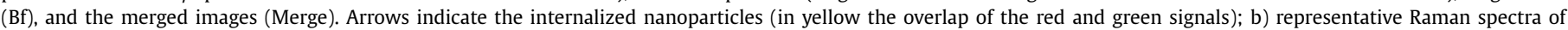

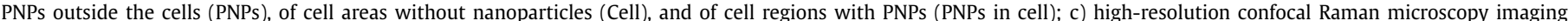

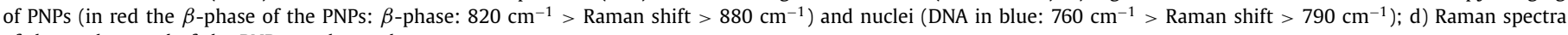
of the nucleus and of the PNPs on the nucleus.

a)

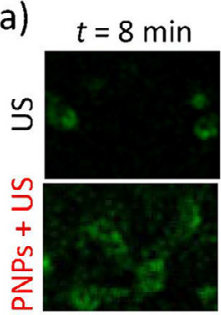

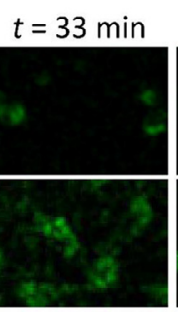
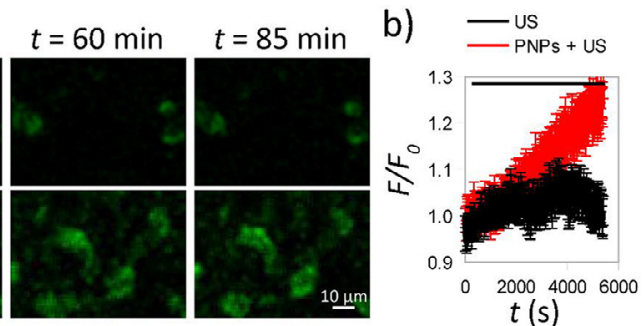

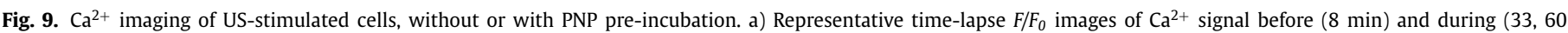

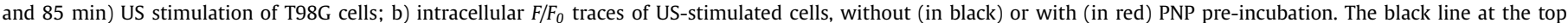
of the graph indicates the period of the chronic US stimulation starting at $t=500 \mathrm{~s}$. 
а)
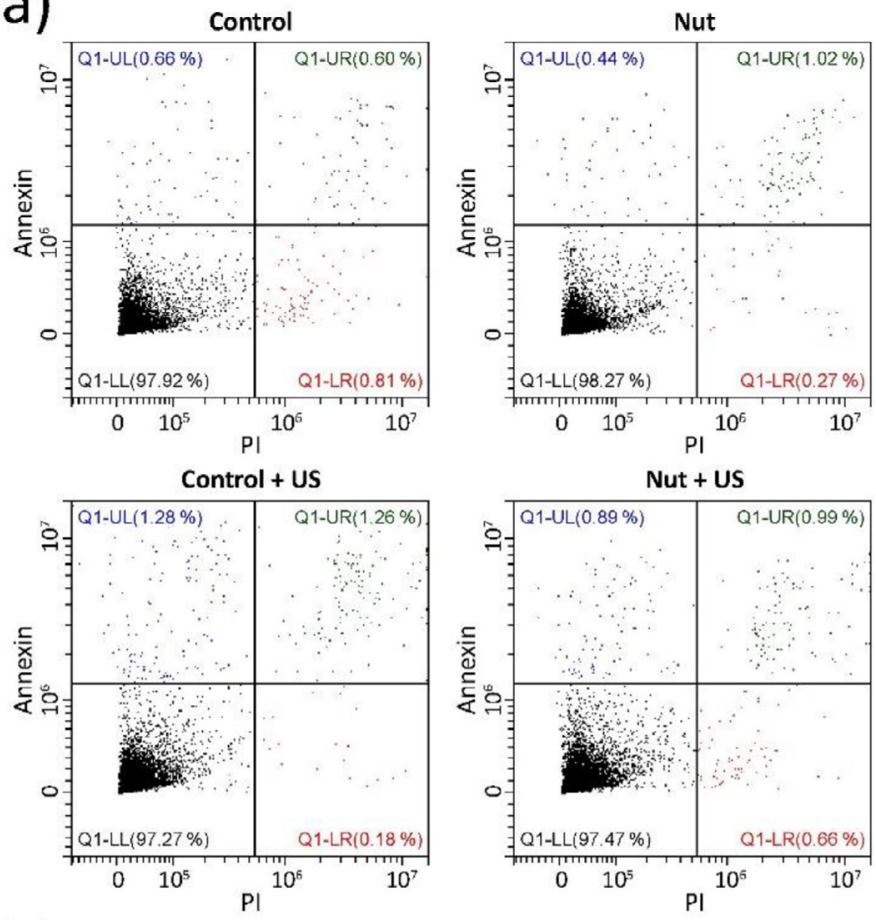
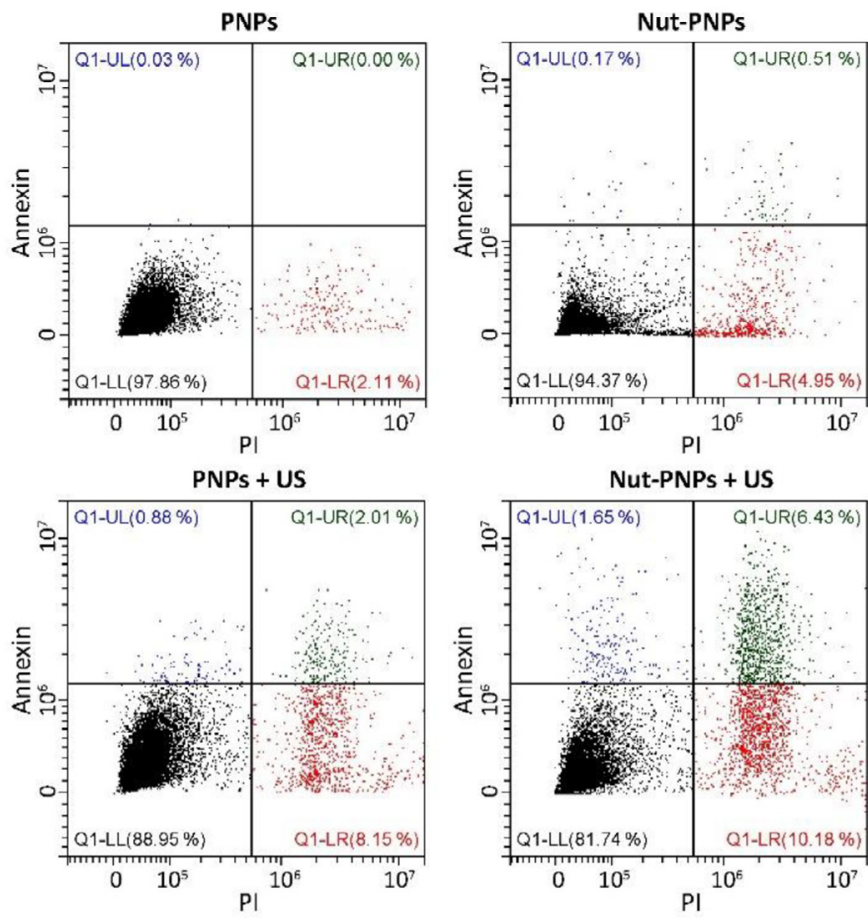

b)

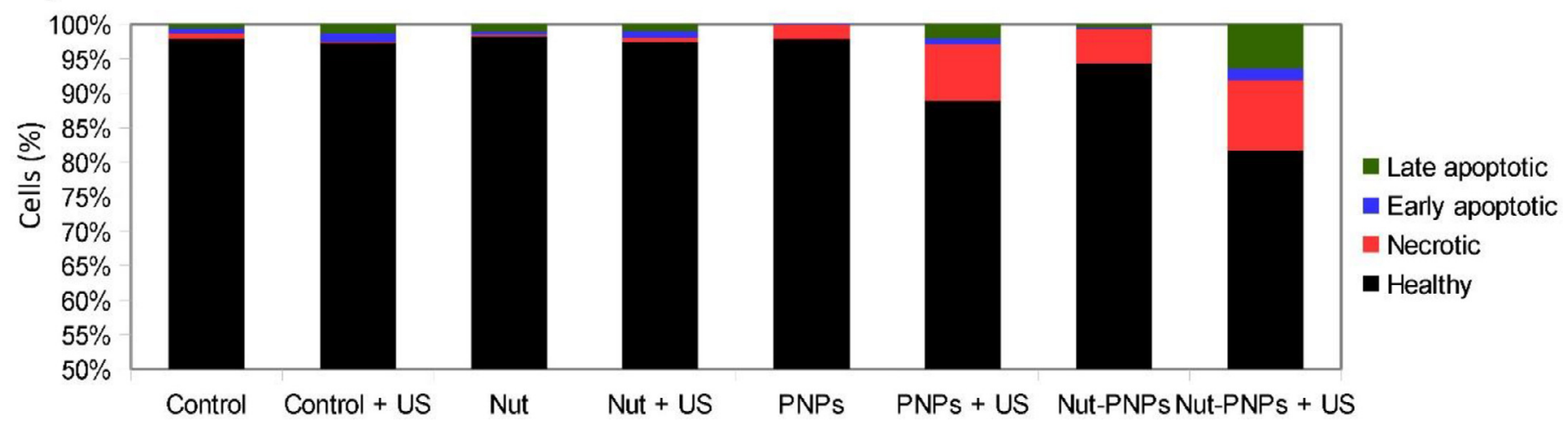

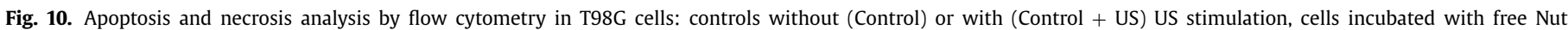

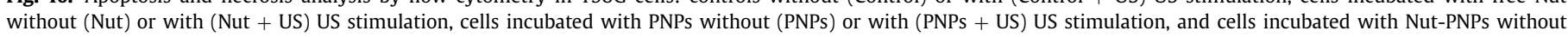

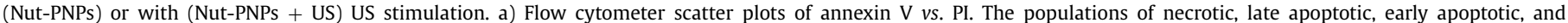
healthy cells have been highlighted with black, blue, red, and green colors, respectively; b) graph reporting the \% of necrotic, late/early apoptotic, and healthy cells.

(Nut + US) US stimulation, cells incubated with PNPs without (PNPs) or with (PNPs + US) US stimulation, and cells incubated with Nut-PNPs without (Nut-PNPs) or with (Nut-PNPs + US) US stimulation. Fig. 10a reports representative flow cytometer scatter plots of annexin V-FITC vs. PI for each experimental condition. The populations of necrotic, late apoptotic, early apoptotic, and healthy cells have been highlighted with black, blue, red, and green colors, respectively. The graph reporting the \% of the necrotic, late/early apoptotic, and healthy cells in the different experimental classes is shown in Fig. 10b. Control cultures were characterized by $0.8 \%$ of necrotic cells, $0.6 \%$ of late apoptotic cells, $0.6 \%$ of early apoptotic cells, and $98.0 \%$ of healthy cells. The most relevant apoptotic/necrotic effects were observed in cultures treated with the combination of piezoelectric stimulation and chemotherapy treatment (Nut-PNPs + US: $10.2 \%$ of necrotic, $6.4 \%$ of late apoptotic, $1.7 \%$ of early apoptotic, and $81.7 \%$ of healthy cells). Minor apoptotic/necrotic effects have been observed in stimulated cultures (PNPs + US: $8.2 \%$ of necrotic, $2.0 \%$ of late apoptotic, $0.9 \%$ of early apoptotic, and $88.9 \%$ of healthy cells) and in cultures treated with
Nut-loaded nanoparticles (Nut-PNPs: $5.0 \%$ of necrotic, $0.5 \%$ of late apoptotic, $0.2 \%$ of early apoptotic, and $94.3 \%$ of healthy cells). These findings indicate as the combined piezoelectric and chemotherapy treatment allowed for the best anticancer outcomes in term of apoptosis and necrosis. Moreover, these results suggest as the decreased cell viability observed in cultures treated with Nut-PNPs (Fig. 6b) is associated with toxicity and necrosis. Interestingly, the treatment with $21.5 \mu \mathrm{M}$ free Nut, which corresponds to the amount of Nut loaded in $500 \mu \mathrm{g} / \mathrm{mL}$ Nut-PNPs, was not able to affect cell viability. The increased toxicity of drug-loaded nanoparticles with respect to the corresponding free drug concentration has been demonstrated in the literature concerning many other cancer models, and can be attributed to the enhanced internalization of the drug in the cells mediated by the nanoparticles [71].

\subsection{Cell motility and invasion}

Cell migration is the directed movement of cells in response to specific mechanical or chemical signals [72], and it is involved in 


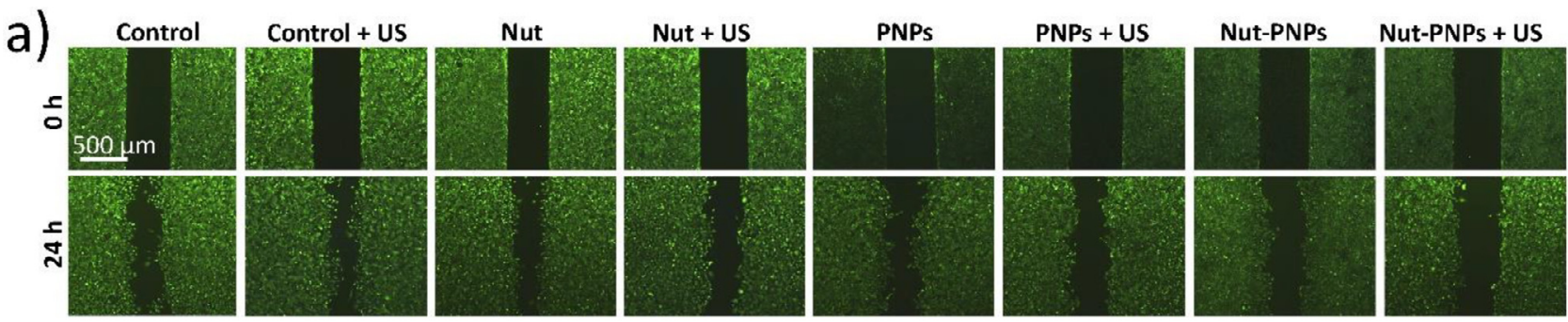

b)
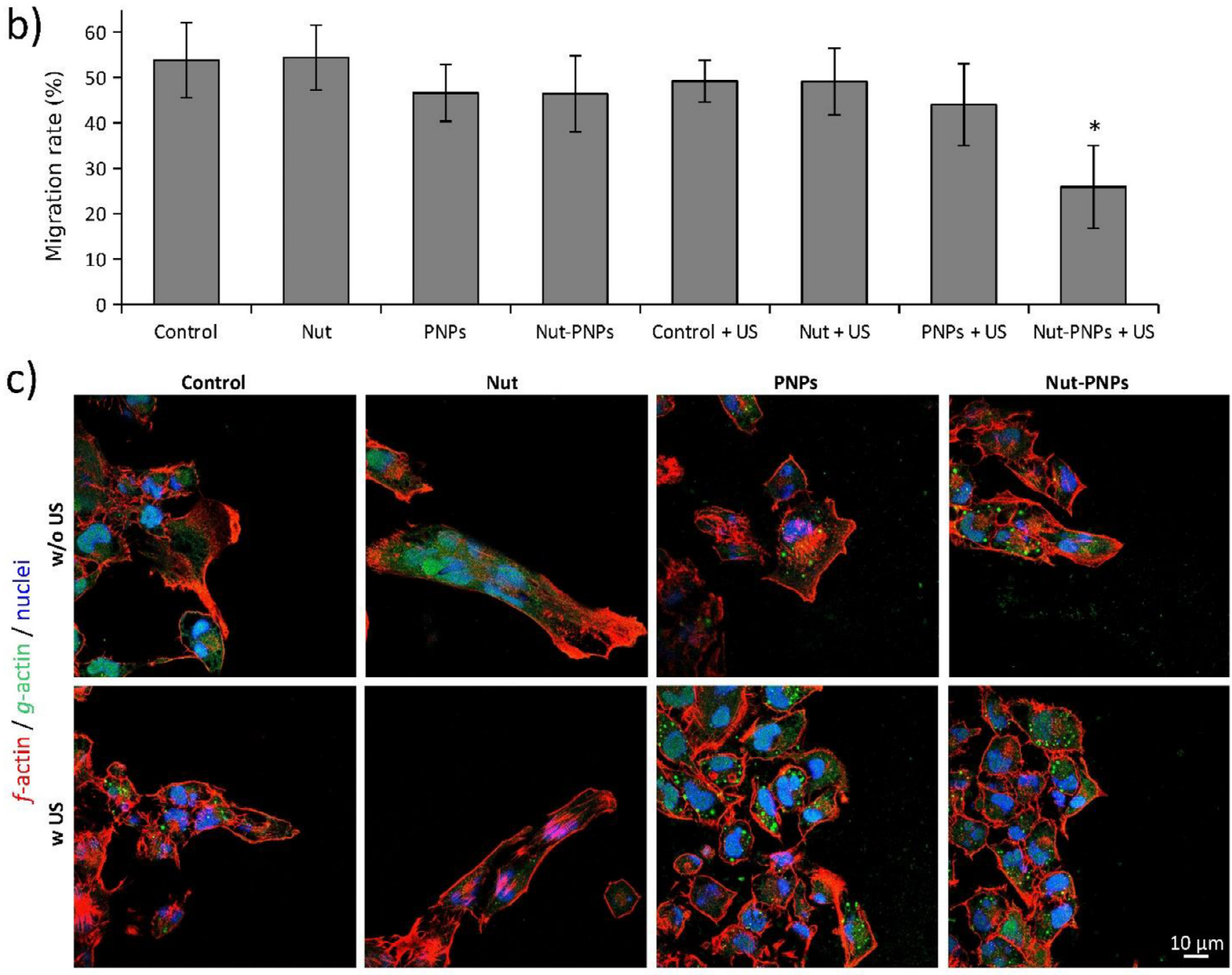

d)

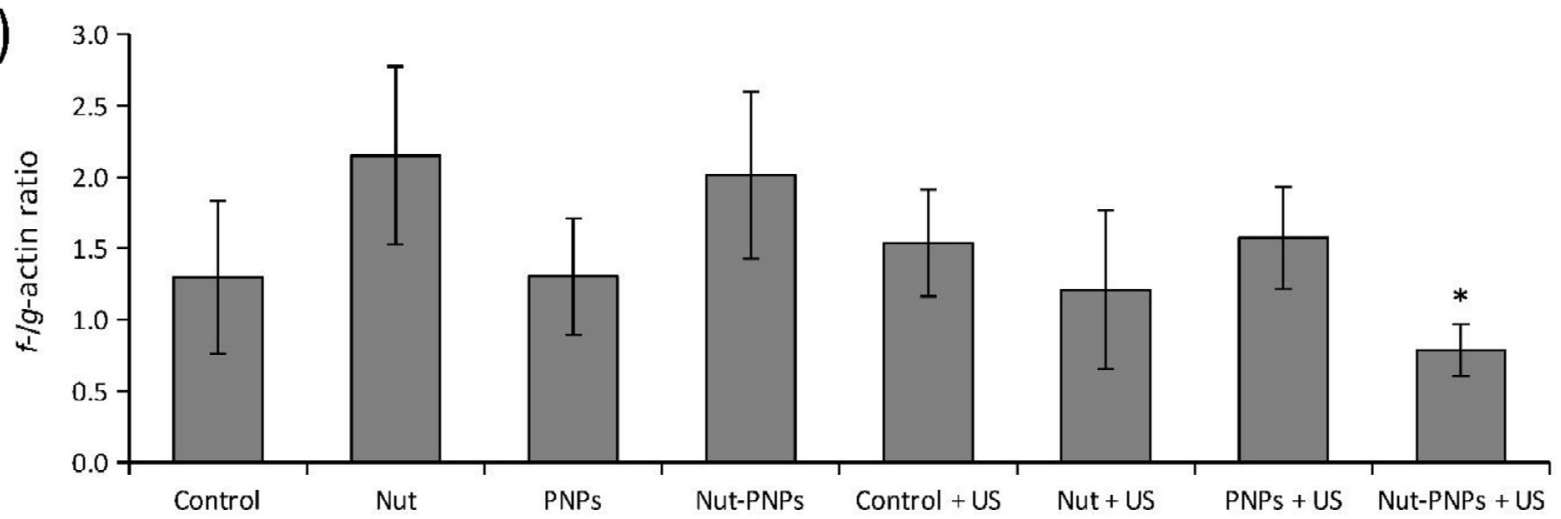

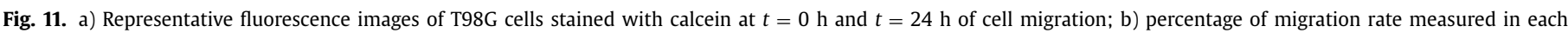

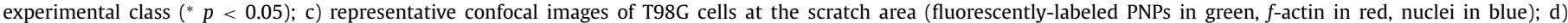
quantification of $f$ - $/ g$-actin ratio during cell migration. ${ }^{*} p<0.05$. 

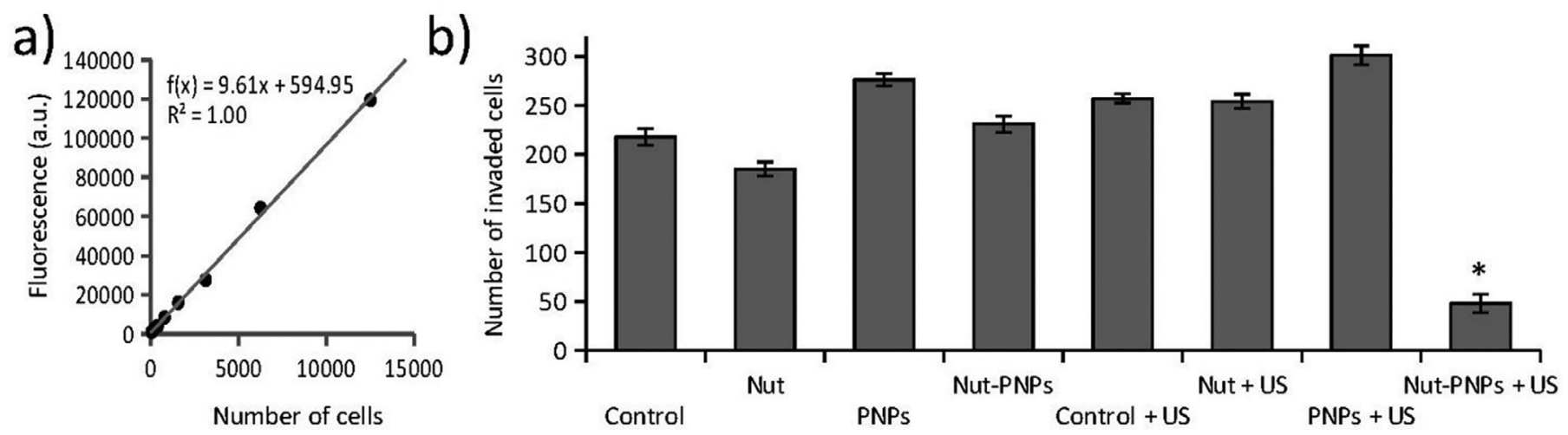

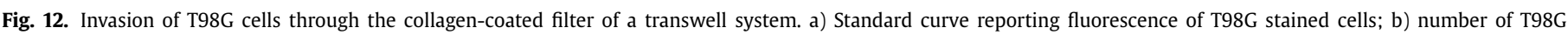
cells that underwent invasion through the collagen-coated filter. ${ }^{*} p<0.05$.

several biological processes including cancer progression, invasiveness and aggressiveness [73]. In this work, in vitro cell migration ability of T98G cells was analyzed to assess their migration ability following piezoelectric stimulation and Nut treatment (Fig. 11). Representative images of the scratch area at $t=0 \mathrm{~h}$ and $t=24$ $\mathrm{h}$ after starting the experiment, and the percentage of migration rate of the 8 experimental classes are reported in Fig. 11a and in Fig. 11b, respectively. The cells treated with Nut-PNPs in the presence of US stimulation (Nut-PNPs + US) showed a reduced migration with respect to the other experimental conditions $(p<0.05)$. Although the bare Nut or PNPs did not affect the migration rate, the combined Nut-PNPs + US treatment significantly decreased the migration rate $(25.8 \pm 9.1 \%)$ with respect to control cultures (Control; migration rate $=53.8 \pm 8.2 \% ; p<0.05$ ).

The actin cytoskeleton has a critical role in organizing cell migration [74]; a characteristic feature of this process is related to the dynamic transition of actin between its monomeric globular $g$-actin and the filamentous $f$-actin form [75]. Fig. 11c shows the confocal fluorescence imaging of T98G cells ( $f$-actin in red, $g$-actin in green, nuclei in blue) after treatment. Excluding Nut-PNPs + US experimental treatment, $f$-actin accumulates in the leading edges of the migrated cells and forms lamellipodia. Front-end protrusion and lamellipodia formation play an important role during cell migration, and are an indication of cell motility [76]. Cells treated with Nut-PNPs + US did not show marked protrusions. Moreover, the ratio between $f$-actin and $g$-actin significantly decreased in these cells (Nut-PNPs + US; $0.78 \pm 0.18$ ) with respect to control cultures (Controls; $1.30 \pm 0.53 ; p<0.05$; Fig. 11d). Since the $f$-actin and $g$-actin respectively represent the polymerized and free monomeric form of actin, the decreased $f$-actin $/ g$ actin ratio indicates a reduced level of actin polymerization, which is a phenomenon required during migration $[77,78]$. The observed cytoskeletal rearrangement is therefore accompanied to a reduced migration level, similarly to analogous situations reported in the literature [79].

Nut is known to reduce cancer cell migration and invasion [80,81], and therefore it may be considered surprising that the treatment with the free drug was not able to reduce motility in our experimental conditions. However, the inhibitory effects of Nut on cell motility, which are known to be mediated by cytoskeletal rearrangements, are limited to p53 wild-type cells [79]. As an example, migration and invasion capabilities of p53-null SAOS osteosarcoma cells are not reduced by $8 \mu \mathrm{M}$ Nut, a concentration able to affect motility in the p53 wild-type H2OS and HT1080 cancer cells. Considering that T98G cells are p53-mutant cells, a decreased effect of Nut is expected in this line [68]. Likely, piezoelectric stimulation enhanced Nut sensitivity in T98G cells. This observation is in line with the literature, where enhanced chemotherapeutic efficacy and reduced drug resistance were observed in different cancer cells $[15,21]$. GBM is described as one of the most aggressive and invasive types of malignant brain tumors in adults [82]; the high mortality rate is mainly due to the extensive invasion of cells to adjacent healthy brain tissue and to the migration along blood vessels that results in a recurrence of disease following the treatment [83]. Cancer cell invasion, i.e., the capability of cells to migrate from one area to another through the extracellular matrix (ECM), includes multiple steps such as the adhesion to the ECM molecules, the degradation of the basement membrane matrix and, finally, the migration through the degraded tissue. Here, the invasion capability of T98G cells through a collagen-coated transwell membrane was investigated. As shown in Fig. 12, the number of cells undergoing invasion that crossed the collagen matrix in the Nut-PNPs + US treatment ( $48 \pm 9$ cells) was strongly reduced with respect to Control (218 \pm 8 cells), as well as with respect to the other experimental conditions ( $185 \pm 7$ cells for Nut; $276 \pm 6$ cells for PNPs; 231 for \pm 8 cells for Nut-PNPs; $257 \pm 5$ cells for Control + US; $254 \pm$ 7 cells for Nut + US; $301 \pm .10$ cells for PNPs + US). The capability of the anticancer treatment to inhibit cell invasion and to induce cell death is considered fundamental for the success of the therapy [84], and our results indicate the effective inhibition of T98G cell invasion in response to the Nut-PNPs + US treatment, in line with the results obtained in the scratch assay (Fig. 11).

\subsection{Proteomic analysis}

Proteomic analyses were performed for all the 8 experimental classes (Control, Nut, PNPs, Nut-PNPs, Control + US, Nut+ US, PNPs+ US, Nut-PNPs+ US; Fig. 13). The principal component analysis (PCA) of the first 2 components (accounting respectively for $15.0 \%$ and $14.1 \%$ of the variance) for each of the 3 performed experiments is reported in Fig. 13a. Basing on PCA, the experimental treatments characterized by the most relevant phenotypic variations with respect to the controls were Nut-PNPs + US, PNPs + US, and Nut-PNPs, experimental classes that also showed significant anticancer effects on T98G cultures (Fig. 10).

Gene ontology (GO) analysis has been carried out to investigate the pathways involved in the observed phenotypic variations. Fig. 13b reports the volcano plot and the GO keywords (downregulated and upregulated pathways are shown in red and green, respectively) regarding the "Nut-PNPs + US vs. Control", "PNPs + US vs. Control", and Nut-PNPs vs. Control" comparisons. In accordance with the PCA analysis, the "Nut-PNPs + US vs. Control" comparison is characterized by the major amount of differently represented proteins (DRPs $=814$ ), followed by "Nut-PNPs vs. Control" (DRPs $=768)$, and by "PNPs + US vs. Control" (DRPs = 367). Significant GO terms involved in Nut-PNP treatment are "inhibition 


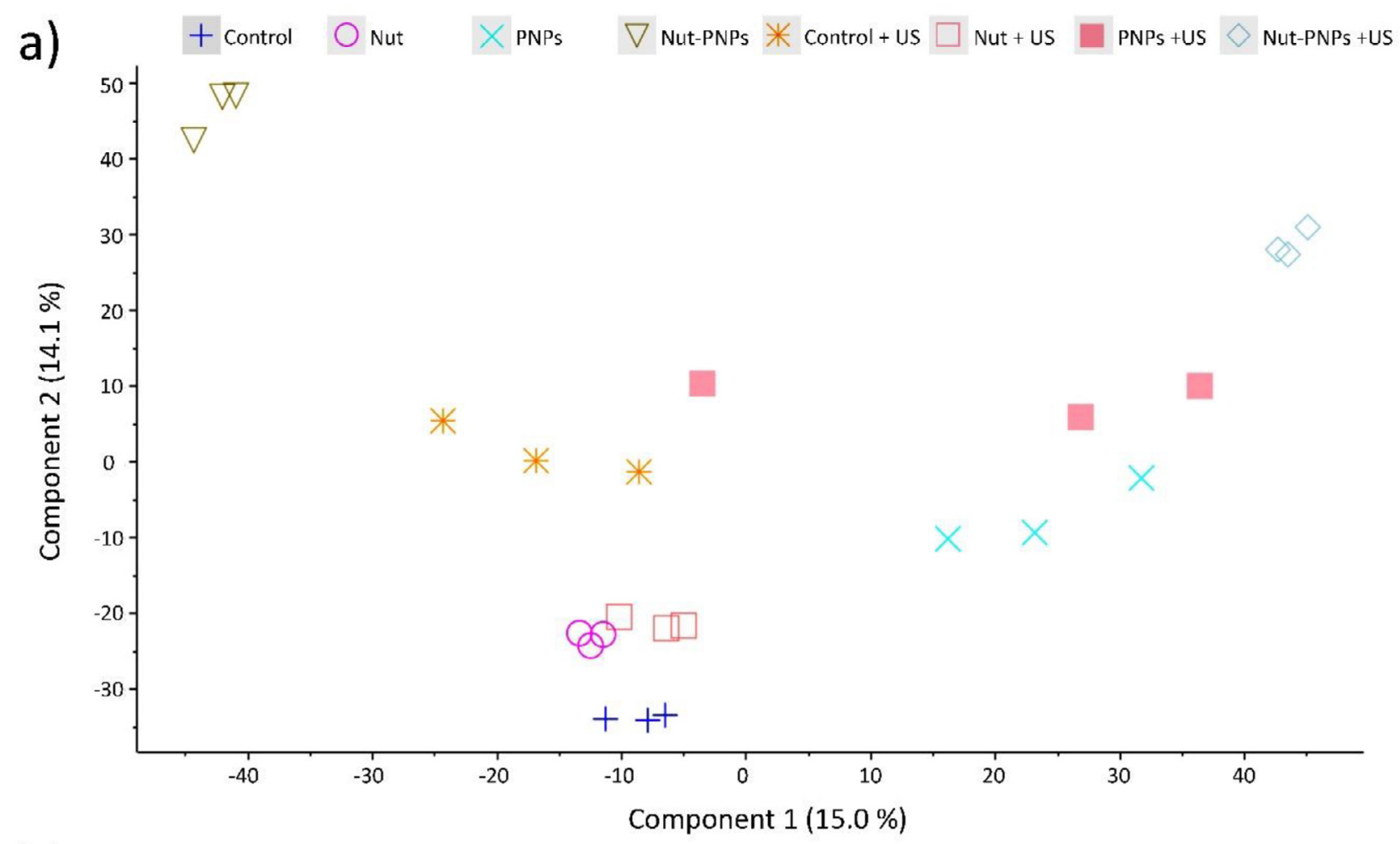

b)

\section{Nut-PNPs vs Control}

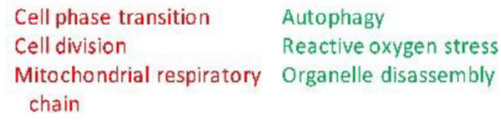

PNPs + US vs Control

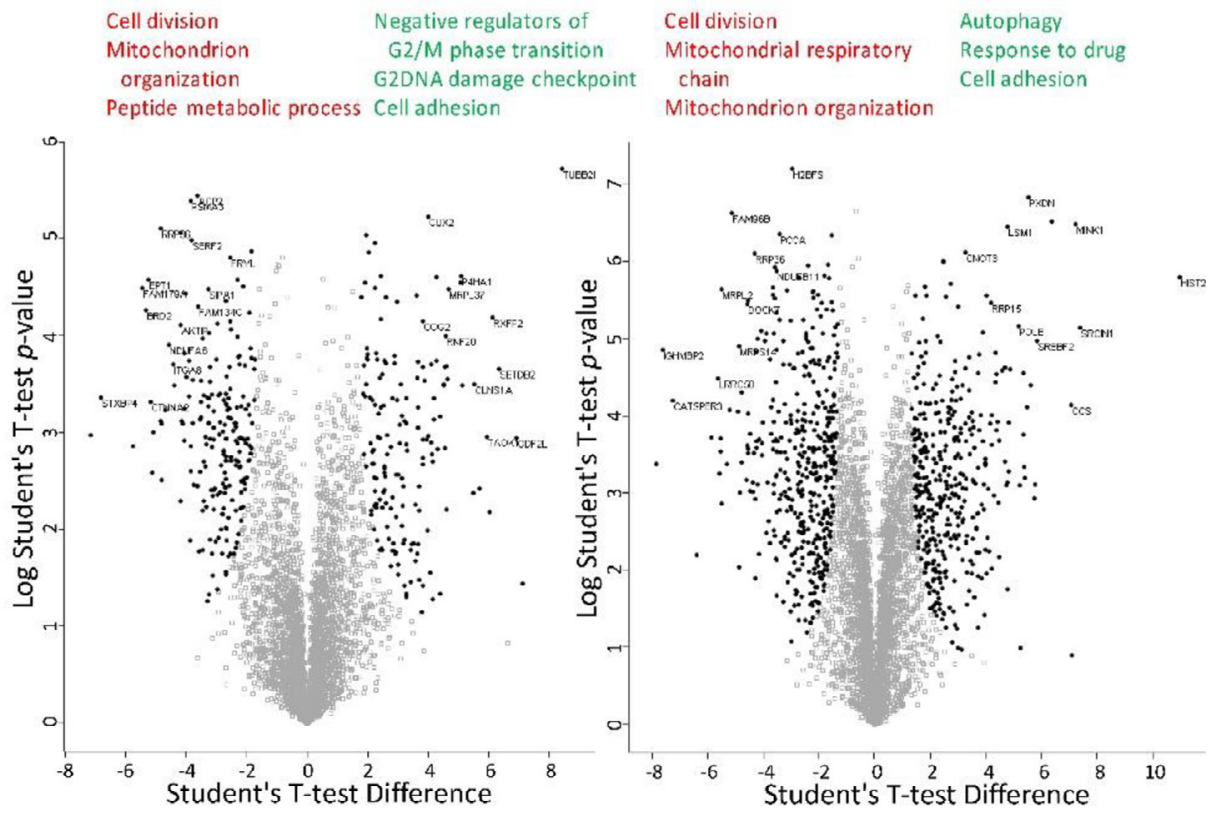

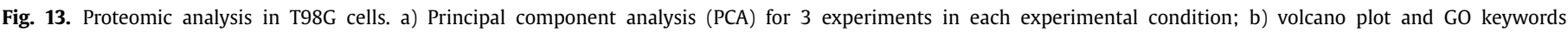

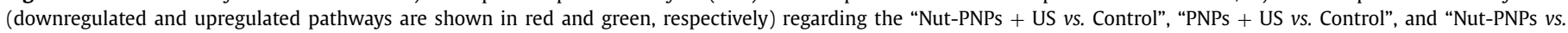
Control" comparisons.

of cell phase transition", "decreased cell division", "inhibition of the mitochondrial respiratory chain", "autophagy", "reactive oxygen stress", and "organelle disassembly". These GO terms indicate the inhibition of cell proliferation and a stress condition induced by the presence of the Nut-loaded particles. It is also worth noticing that one of the upregulated pathways in cells treated with NutPNPs + US is that related to cell responsiveness to drugs (Fig. 13.b). This higher sensitivity to drugs might justify the higher anti-tumor efficacy of Nut-PNPs + US with respect to the non-stimulated counterpart. In these conditions, in fact, we can assume that even a low increase in drug concentration in the intracellular compartment, as evidenced by nutlin-3a release from Nut-PNPs upon US exposure (Fig. 4) can favor toxicity in a more efficient way, as compared to control group without US. Therefore, a higher sensitivity of the cells and a slightly higher concentration of nutlin-3a can cooperate in boosting the anti-tumor activity of Nut-PNPs when 
US is applied. Concerning the effects of piezoelectric stimulation, "PNPs + US vs. Control", GO terms report an "inhibition of cell division", accompanied by a "reduced peptide metabolic process", "inhibition of mitochondrial organization", and negative regulation of "G/M phase transition". These GO terms indicate a decreased cell metabolism and an inhibition of cell division. Furthermore, in "PNPs + US vs. Control" and in "Nut-PNPs + US vs. Control" comparisons, the promotion of "cell adhesion" pathways has been observed. This phenomenon is particularly important to counteract the epithelial-mesenchymal transition (EMT) [85]. The acquisition of the mesenchymal phenotype by glioblastoma cells after EMT is associated with increased cell motility and drug resistance, and is involved in glioblastoma progression [86]. The complete list of the GO terms has been reported as Supplementary Information as Table S1-S6.

The reduced cell migration rate observed in Nut-PNPs + US and in PNPs + US stimulated cultures with respect to controls may be associated with the upregulation of the "cell adhesion" pathways; however, it is important to highlight as just in Nut-PNPs + US cultures the reduction in migration rate was statistically significant. In this regard, Nut may play a supporting role in reducing motility in response to piezoelectric stimulation $[79,80]$.

\section{Conclusions}

In this work, we successfully synthesized piezoelectric hybrid lipid-polymeric nanoparticles, efficiently encapsulating a nongenotoxic drug (nutlin-3a), and functionalized with a peptide (ApoE), that enhances their passage through the BBB. Upon US exposure, PNPs were able to induce a cellular response in terms of $\mathrm{Ca}^{2+}$ channel activation, proving the production of an effective electrical cue. Nutlin-loaded PNPs exerted only a mild cytotoxic effect on T98G glioblastoma cells; however, the induction of a US stimulus significantly improved their therapeutic efficacy. In particular, Nut-PNPs upon US exposure were able to reduce cell migration, actin polymerization, and invasion ability of T98G cells, while fostering apoptotic and necrotic events; from proteomic analysis, significant GO terms involved in this combined treatment resulted to be the "inhibition of cell division", "promotion of autophagy", and "promotion of cell adhesion" pathways. Taken all together, these results clearly show the potentialities of biocompatible organic piezoelectric nanomaterials and ultrasound stimulation in the treatment of extremely aggressive and invasive cancers such as glioblastoma. Moreover, wireless activation of the anticancer action paves the way to a less invasive, more focused and efficient approach that could potentially target also deep-seated tumors, without recurring to surgical intervention or invasive therapeutic protocols.

\section{Disclosure}

The authors declare that they have no known competing financial interests or personal relationships that could have appeared to influence the work reported in this paper.

\section{Declaration of Competing Interest}

The authors declare that they have no known competing financial interests or personal relationships that could have appeared to influence the work reported in this paper.

\section{Acknowledgements}

This work has received funding from the European Research Council (ERC) under the European Union's Horizon 2020 research and innovation program (grant agreement $\mathrm{N}^{\circ} 709613$, SLaMM). The authors would also like to acknowledge Mr. Carlo Filippeschi (Istituto Italiano di Tecnologia, Italy) and Dr. Giammarino Pugliese (Istituto Italiano di Tecnologia, Italy) for their support in SEM analysis and in TGA measurements, respectively.

\section{Supplementary materials}

Supplementary material associated with this article can be found, in the online version, at doi:10.1016/j.actbio.2021.04.005.

\section{References}

[1] A. Degl'Innocenti, N. di Leo, G. Ciofani, Genetic Hallmarks and Heterogeneity of Glioblastoma in the Single-Cell Omics Era, Adv. Ther. 3 (2020) 1900152, doi:10. 1002/adtp.201900152.

[2] E.C. Holland, Glioblastoma multiforme: The terminator, Proc. Natl. Acad. Sci. U. S. A. 97 (2000) 6242-6244, doi:10.1073/pnas.97.12.6242.

[3] J.R.D. Pearson, T. Regad, Targeting cellular pathways in glioblastoma multiforme, Signal Transduct. Target. Ther. 2 (2017) 1-11, doi:10.1038/sigtrans.2017. 40.

[4] R. Jelsma, P.C. Bucy, The treatment of glioblastoma multiforme of the brain, J. Neurosurg. 27 (1967) 388-400, doi:10.3171/jns.1967.27.5.0388.

[5] N. Ishii, M. Tada, M.F. Hamou, R.C. Janzer, K. Meagher-Villemure, O.D. Wiestler, N. De Tribolet, E.G. Van Meir, Cells with TP53 mutations in low grade astrocytic tumors evolve clonally to malignancy and are an unfavorable prognostic factor, Oncogene (1999), doi:10.1038/sj.onc.1203241.

[6] W.M. Pardridge, Drug targeting to the brain, Pharm. Res. (2007), doi:10.1007/ s11095-007-9324-2.

[7] C.P. Haar, P. Hebbar, G.C. Wallace, A. Das, W.A. Vandergrift, J.A. Smith, P. Giglio, S.J. Patel, S.K. Ray, N.L. Banik, Drug resistance in glioblastoma: a mini review, Neurochem. Res. 37 (2012) 1192-1200, doi:10.1007/s11064-011-0701-1.

[8] C. Martinelli, C. Pucci, G. Ciofani, Nanostructured carriers as innovative tools for cancer diagnosis and therapy, APL Bioeng. 3 (2019), doi:10.1063/1.5079943.

[9] C. Pucci, C. Martinelli, G. Ciofani, Innovative approaches for cancer treatment: Current perspectives and new challenges, Ecancermedicalscience 13 (2019) 126, doi:10.3332/ecancer.2019.961.

[10] D. Hymel, B.R. Peterson, Synthetic cell surface receptors for delivery of therapeutics and probes, Adv. Drug Deliv. Rev. (2012), doi:10.1016/j.addr.2012.02. 007

[11] H. Gao, Progress and perspectives on targeting nanoparticles for brain drug delivery, Acta Pharm. Sin. B. 6 (2016) 268-286, doi:10.1016/j.apsb.2016.05.013.

[12] J. Li, H. Duan, K. Pu, Nanotransducers for near-infrared photoregulation in biomedicine, Adv. Mater. 31 (2019), doi:10.1002/adma.201901607.

[13] J. Yang, Z. Shi, R. Liu, Y. Wu, X. Zhang, Combined-therapeutic strategies synergistically potentiate glioblastoma multiforme treatment via nanotechnology, Theranostics 10 (2020) 3223-3239, doi:10.7150/thno.40298.

[14] A. Marino, A. Camponovo, A. Degl'Innocenti, M. Bartolucci, C. Tapeinos, C. Martinelli, D. De Pasquale, F. Santoro, V. Mollo, S. Arai, M. Suzuki, Y. Harada, A. Petretto, G. Ciofani, Multifunctional temozolomide-loaded lipid superparamagnetic nanovectors: dual targeting and disintegration of glioblastoma spheroids by synergic chemotherapy and hyperthermia treatment, Nanoscale 11 (2019) 21227-21248, doi:10.1039/c9nr07976a.

[15] A. Marino, E. Almici, S. Migliorin, C. Tapeinos, M. Battaglini, V. Cappello, M. Marchetti, G. de Vito, R. Cicchi, F.S. Pavone, G. Ciofani, Piezoelectric barium titanate nanostimulators for the treatment of glioblastoma multiforme, J. Colloid Interface Sci. 538 (2019) 449-461, doi:10.1016/j.jcis.2018.12.014.

[16] L. Liu, B. Chen, K. Liu, J. Gao, Y. Ye, Z. Wang, N. Qin, D.A. Wilson, Y. Tu, F. Peng, Wireless manipulation of magnetic/piezoelectric micromotors for precise neural stem-like cell stimulation, Adv. Funct. Mater. 30 (2020) 1910108, doi:10.1002/adfm.201910108.

[17] A. Cafarelli, A. Verbeni, A. Poliziani, P. Dario, A. Menciassi, L. Ricotti, Tuning acoustic and mechanical properties of materials for ultrasound phantoms and smart substrates for cell cultures, Acta Biomater. 49 (2017) 368-378, doi:10. 1016/j.actbio.2016.11.049.

[18] B. Ma, F. Liu, Z. Li, J. Duan, Y. Kong, M. Hao, S. Ge, H. Jiang, H. Liu, Piezoelectric nylon-11 nanoparticles with ultrasound assistance for high-efficiency promotion of stem cell osteogenic differentiation, J. Mater. Chem. B. 7 (2019) 1847-1854, doi:10.1039/c8tb03321h.

[19] A. Marino, S. Arai, Y. Hou, E. Sinibaldi, M. Pellegrino, Y.T. Chang, B. Mazzolai, V. Mattoli, M. Suzuki, G. Ciofani, Piezoelectric nanoparticle-assisted wireless neuronal stimulation, ACS Nano 9 (2015) 7678-7689, doi:10.1021/acsnano. 5b03162.

[20] A. Marino, M. Battaglini, D. De Pasquale, A. Degl'Innocenti, G. Ciofani, Ultrasound-activated piezoelectric nanoparticles inhibit proliferation of breast cancer cells, Sci. Rep. 8 (2018), doi:10.1038/s41598-018-24697-1.

[21] D. Janigro, C. Perju, V. Fazio, K. Hallene, G. Dini, M.K. Agarwal, L. Cucullo, Alternating current electrical stimulation enhanced chemotherapy: a novel strategy to bypass multidrug resistance in tumor cells, BMC Cancer 6 (2006) 72, doi:10.1186/1471-2407-6-72.

[22] R. Stupp, S. Taillibert, A. Kanner, W. Read, D.M. Steinberg, B. Lhermitte, S. Toms, A. Idbaih, M.S. Ahluwalia, K. Fink, F. Di Meco, F. Lieberman, J.J. Zhu, G. Stragliotto, D.D. Tran, S. Brem, A.F. Hottinger, E.D. Kirson, G. Lavy-Shahaf, U. Weinberg, C.Y. Kim, S.H. Paek, G. Nicholas, J. Burna, H. Hirte, M. Weller, 
Y. Palti, M.E. Hegi, Z. Ram, Effect of tumor-treating fields plus maintenance temozolomide vs maintenance temozolomide alone on survival in patients with glioblastoma a randomized clinical trial, JAMA - J. Am. Med. Assoc. 318 (2017) 2306-2316, doi:10.1001/jama.2017.18718.

[23] L. Cucullo, G. Dini, K.L. Hallene, V. Fazio, E.V. Ilkanich, C. Igboechi, K.M. Kight, M.K. Agarwal, M. Garrity-Moses, D. Janigro, Very low intensity alternating current decreases cell proliferation, Glia 51 (2005) 65-72, doi:10.1002/glia.20188.

[24] K. Kapat, Q.T.H. Shubhra, M. Zhou, S. Leeuwenburgh, Piezoelectric nanobiomaterials for biomedicine and tissue regeneration, Adv. Funct. Mater. 30 (2020) 1909045, doi:10.1002/adfm.201909045.

[25] G.G. Genchi, L. Ceseracciu, A. Marino, M. Labardi, S. Marras, F. Pignatelli, L. Bruschini, V. Mattoli, G. Ciofani, P(VDF-TrFE)/BaTiO3 nanoparticle composite films mediate piezoelectric stimulation and promote differentiation of SHSY5Y neuroblastoma cells, Adv. Healthc. Mater. 5 (2016) 1808-1820, doi:10. 1002/adhm.201600245.

[26] P. Hitscherich, S. Wu, R. Gordan, L.H. Xie, T. Arinzeh, E.J. Lee, The effect of PVDF-TrFE scaffolds on stem cell derived cardiovascular cells, Biotechnol. Bioeng. 113 (2016) 1577-1585, doi:10.1002/bit.25918.

[27] G.G. Genchi, E. Sinibaldi, L. Ceseracciu, M. Labardi, A. Marino, S. Marras, G. De Simoni, V. Mattoli, G. Ciofani, Ultrasound-activated piezoelectric P(VDF$\mathrm{TrFE}$ )/boron nitride nanotube composite films promote differentiation of human SaOS-2 osteoblast-like cells, Nanomedicine Nanotechnology, Biol. Med. 14 (2018) 2421-2432, doi:10.1016/j.nano.2017.05.006.

[28] Z. Xiao, O. Dong, P. Sharma, Y. Yuan, B. Mao, W. Tian, A. Gruverman, J. Huang, Synthesis and application of ferroelectric P(VDF-TrFE) nanoparticles in organic photovoltaic devices for high efficiency, Adv. Energy Mater. 3 (2013) 15811588, doi:10.1002/aenm.201300396.

[29] T. Date, V. Nimbalkar, J. Kamat, A. Mittal, R.I. Mahato, D. Chitkara, Lipidpolymer hybrid nanocarriers for delivering cancer therapeutics, J. Control. Release. 271 (2018) 60-73, doi:10.1016/j.jconrel.2017.12.016.

[30] P. Chène, Inhibiting the p53-MDM2 interaction: An important target for cancer therapy, Nat. Rev. Cancer. 3 (2003) 102-109, doi:10.1038/nrc991.

[31] P. Secchiero, F. Corallini, A. Gonelli, R. Dell'Eva, M. Vitale, S. Capitani, A. Albini, G. Zauli, Antiangiogenic activity of the MDM2 antagonist nutlin-3, Circ. Res. 100 (2007) 61-69, doi:10.1161/01.RES.0000253975.76198.ff.

[32] F. Re, I. Cambianica, C. Zona, S. Sesana, M. Gregori, R. Rigolio, B.La Ferla, F. Nicotra, G. Forloni, A. Cagnotto, M. Salmona, M. Masserini, G. Sancini, Functionalization of liposomes with ApoE-derived peptides at different density affects cellular uptake and drug transport across a blood-brain barrier model, Nanomedicine Nanotechnology, Biol. Med. 7 (2011) 551-559, doi:10.1016/j. nano.2011.05.004

[33] B. Dehouck, L. Fenart, M.P. Dehouck, A. Pierce, G. Torpier, R. Cecchelli, A new function for the LDL receptor: transcytosis of LDL across the blood-brain barrier, J. Cell Biol. 138 (1997) 877-889, doi:10.1083/jcb.138.4.877.

[34] Y. Jiang, J. Zhang, F. Meng, Z. Zhong, Apolipoprotein e peptide-directed chimeric polymersomes mediate an ultrahigh-efficiency targeted protein therapy for glioblastoma, ACS Nano 12 (2018) 11070-11079, doi:10.1021/acsnano. 8 b05265.

[35] J.A.R. Nicoll, E. Zunarelli, R. Rampling, L.S. Murray, V. Papanastassiou, J. Stewart, Involvement of apolipoprotein $\mathrm{E}$ in glioblastoma: Immunohistochemistry and clinical outcome, Neuroreport 14 (2003) 1923-1926, doi:10.1097| 00001756-200310270-00008.

[36] V. Sencadas, V.M. Moreira, S. Lanceros-Mendéz, A.S. Pouzada, R. Gregório, $\alpha-$ To - $\beta$ transformation on PVDF films obtained by uniaxial stretch, Mater. Sci. Forum (2006), doi:10.4028/www.scientific.net/msf.514-516.872.

[37] P. Martins, A.C. Lopes, S. Lanceros-Mendez, Electroactive phases of poly(vinylidene fluoride): determination, processing and applications, Prog. Polym. Sci. 39 (2014) 683-706, doi:10.1016/j.progpolymsci.2013.07.006.

[38] F. Xu, K. Zhang, Y. Zhou, Z. Qu, H. Wang, Y. Zhang, H. Zhou, C. Yan, Facile preparation of highly oriented poly(vinylidene fluoride) uniform films and their ferro- and piezoelectric properties, RSC Adv. 7 (2017) 17038-17043, doi:10.1039/c7ra00586e.

[39] C. Pucci, D. De Pasquale, A. Marino, C. Martinelli, S. Lauciello, G. Ciofani, Hybrid magnetic nanovectors promote selective glioblastoma cell death through a combined effect of lysosomal membrane permeabilization and chemotherapy, ACS Appl. Mater. Interfaces. 12 (2020) 29037-29055, doi:10.1021/acsami. 0c05556.

[40] D. De Pasquale, A. Marino, C. Tapeinos, C. Pucci, S. Rocchiccioli, E. Michelucci, F. Finamore, L. McDonnell, A. Scarpellini, S. Lauciello, M. Prato, A. Larrañaga, F. Drago, G. Ciofani, Homotypic targeting and drug delivery in glioblastoma cells through cell membrane-coated boron nitride nanotubes, Mater. Des. 192 (2020), doi:10.1016/j.matdes.2020.108742.

[41] I. Papademetriou, E. Vedula, J. Charest, T. Porter, Effect of flow on targeting and penetration of angiopep-decorated nanoparticles in a microfluidic model blood-brain barrier, PLoS One 13 (2018) 1-18, doi:10.1371/journal.pone. 0205158.

[42] A. Siflinger-Birnboim, P.J. del Vecchio, J.A. Cooper, F.A. Blumenstock, J.M. Shepard, A.B. Malik, Molecular sieving characteristics of the cultured endothelial monolayer, J. Cell. Physiol. 132 (1987) 111-117, doi:10.1002/jcp.1041320115.

[43] M. Heymans, E. Sevin, F. Gosselet, S. Lundquist, M. Culot, Mimicking brain tissue binding in an in vitro model of the blood-brain barrier illustrates differences between in vitro and in vivo methods for assessing the rate of brain penetration, Eur. J. Pharm. Biopharm. 127 (2018) 453-461, doi:10.1016/j.ejpb. 2018.03.007.

[44] A.D. Wong, M. Ye, A.F. Levy, J.D. Rothstein, D.E. Bergles, P.C. Searson, The blood- brain barrier: an engineering perspective, Front. Neuroeng. 6 (2013) 1-22, doi:10.3389/fneng.2013.00007.

[45] A Marino, S. Arai, Y. Hou, A Degl'Innocenti, V. Cappello, B. Mazzolai, Y.T. Chang, V. Mattoli, M. Suzuki, G. Ciofani, Gold nanoshell-mediated remote myotube activation, ACS Nano 11 (2017) 2494-2505, doi:10.1021/acsnano. 6b08202.

[46] S. Rivas-Arancibia, E. Rodríguez-Martínez, I. Badillo-Ramírez, U. LópezGonzález, J.M. Saniger, Structural changes of amyloid beta in hippocampus of rats exposed to ozone: a Raman spectroscopy study, Front. Mol. Neurosci. 10 (2017), doi:10.3389/fnmol.2017.00137.

[47] K.A. Okotrub, N.V. Surovtsev, V.F. Semeshin, L.V. Omelyanchuk, Raman spectroscopy for DNA quantification in cell nucleus, Cytom. Part A. 87 (2015) 6873, doi:10.1002/cyto.a.22585.

[48] D.A. Guzmán-Embús, M. Orrego Cardozo, C. Vargas-Hernández, Genomic DNA characterization of pork spleen by Raman spectroscopy, J. Appl. Phys. 114 (2013) 194704, doi:10.1063/1.4831948

[49] C. Rojas, M. Tedesco, P. Massobrio, A. Marino, G. Ciofani, S. Martinoia, R. Raiteri, Acoustic stimulation can induce a selective neural network response mediated by piezoelectric nanoparticles, J. Neural Eng. 15 (2018), doi:10.1088/1741-2552/ aaa 140.

[50] C. Tapeinos, A. Marino, M. Battaglini, S. Migliorin, R. Brescia, A. Scarpellini, C. De Julián Fernández, M. Prato, F. Drago, G. Ciofani, Stimuli-responsive lipidbased magnetic nanovectors increase apoptosis in glioblastoma cells through synergic intracellular hyperthermia and chemotherapy, Nanoscale 11 (2019) 72-88, doi:10.1039/c8nr05520c.

[51] N.A. Kulak, G. Pichler, I. Paron, N. Nagaraj, M. Mann, Minimal, encapsulated proteomic-sample processing applied to copy-number estimation in eukaryotic cells, Nat. Methods. 11 (2014) 319-324, doi:10.1038/nmeth.2834.

[52] J. Cox, M. Mann, MaxQuant enables high peptide identification rates, individualized p.p.b.-range mass accuracies and proteome-wide protein quantification, Nat. Biotechnol. 26 (2008) 1367-1372, doi:10.1038/nbt.1511.

[53] S. Tyanova, T. Temu, P. Sinitcyn, A. Carlson, M.Y. Hein, T. Geiger, M. Mann, J. Cox, The Perseus computational platform for comprehensive analysis of (prote)omics data, Nat. Methods. 13 (2016) 731-740, doi:10.1038/nmeth.3901.

[54] C.S. Greene, A. Krishnan, A.K. Wong, E. Ricciotti, R.A. Zelaya, D.S. Himmelstein, R. Zhang, B.M. Hartmann, E. Zaslavsky, S.C. Sealfon, D.I. Chasman, G.A. FitzGerald, K. Dolinski, T. Grosser, O.G. Troyanskaya, Understanding multicellular function and disease with human tissue-specific networks, Nat. Genet. 47 (2015) 569, doi: $10.1038 / \mathrm{NG} .3259$.

[55] N. Meng, X. Zhu, R. Mao, M.J. Reece, E. Bilotti, Nanoscale interfacial electroactivity in PVDF /PVDF-TrFE blended films with enhanced dielectric and ferroelectric properties †, J. Mater. Chem. C. 5 (2017) 3296-3305, doi:10.1039/ c7tc00162b.

[56] A.J. Lovinger, T. Furukawa, G.T. Davis, M.G. Broadhurst, Crystallographic changes characterizing the Curie transition in three ferroelectric copolymers of vinylidene fluoride and trifluoroethylene: 1. As-crystallized samples, Polymer (Guildf) 24 (1983) 1225-1232, doi:10.1016/0032-3861(83)90050-2.

[57] A.J. Lovinger, Ferroelectric Polymers, Science (80-.) 220 (1983) 1115-1121.

[58] G.T. Davis, J.E. McKinney, M.G. Broadhurst, S.C. Roth, Electric-field-induced phase changes in poly(vinylidene fluoride), J. Appl. Phys. 49 (1978) 4998, doi:10.1063/1.324446.

[59] K. Matsushige, K. Nagata, S. Imada, T. Takemura, The II-I crystal transformation of poly(vinylidene fluoride) under tensile and compressional stresses, Polymer (Guildf) 21 (1980) 1391-1397, doi:10.1016/0032-3861(80)90138-X.

[60] G. Teyssedre, DSC and TSC study of a VDF/TrFE copolymer, Thermochim. Acta. 226 (1993) 65-75

[61] F. Bahadori, G. Topçu, M.S. Ero, H. Önyüksel, A New Lipid-Based Nano Formulation of Vinorelbine, AAPS PharmSciTech 15 (2014) 1138-1148, doi:10.1208/ s12249-014-0146-3.

[62] A.M. Alkilany, L. Zhu, H. Weller, A. Mews, W.J. Parak, M. Barz, N. Feliu, Ligand density on nanoparticles: A parameter with critical impact on nanomedicine, Adv. Drug Deliv. Rev. 143 (2019) 22-36, doi:10.1016/j.addr.2019.05.010.

[63] S. Santaguida, D. Janigro, M. Hossain, E. Oby, E. Rapp, L. Cucullo, Side by side comparison between dynamic versus static models of blood-brain barrier in vitro: A permeability study, Brain Res 1109 (2006) 1-13, doi:10.1016/j.brainres. 2006.06.027.

[64] H. Xu, Z. Li, Y. Yu, S. Sizdahkhani, W.S. Ho, F. Yin, L. Wang, G. Zhu, M. Zhang, L. Jiang, Z. Zhuang, J. Qin, A dynamic in vivo-like organotypic blood-brain barrier model to probe metastatic brain tumors, Sci. Rep. 6 (2016) 36670 , doi:10.1038/srep36670.

[65] B.B. Weksler, E.A. Subileau, N. Perrière, P. Charneau, K. Holloway, M. Leveque, H. Tricoire-Leignel, A. Nicotra, S. Bourdoulous, P. Turowski, D.K. Male, F. Roux J. Greenwood, I.A. Romero, P.O. Couraud, Blood-brain barrier-specific properties of a human adult brain endothelial cell line, FASEB J 19 (2005) 1872-1874, doi:10.1096/fj.04-3458fje.

[66] H.C. Helms, N.J. Abbott, M. Burek, R. Cecchelli, P.O. Couraud, M.A. Deli, C. Förster, H.J. Galla, I.A. Romero, E.V. Shusta, M.J. Stebbins, E. Vandenhaute, B. Weksler, B. Brodin, In vitro models of the blood-brain barrier: An overview of commonly used brain endothelial cell culture models and guidelines for their use, J. Cereb. Blood Flow Metab. 36 (2015) 862-890, doi:10.1177| $0271678 X 16630991$.

[67] B. Dehouck, M.P. Dehouck, J.C. Fruchart, R. Cecchelli, Upregulation of the low density lipoprotein receptor at the blood-brain barrier: Intercommunications between brain capillary endothelial cells and astrocytes, J. Cell Biol. 126 (1994) 465-473, doi:10.1083/jcb.126.2.465.

[68] R. Villalonga-Planells, L. Coll-Mulet, F. Martínez-Soler, E. Castaño, J.J. Acebes, 
P. Giménez-Bonafé, J. Gil, A. Tortosa, Activation of p53 by nutlin-3a induces apoptosis and cellular senescence in human glioblastoma multiforme, PLoS One 6 (2011) 18588, doi:10.1371/journal.pone.0018588.

[69] E. Fröhlich, The role of surface charge in cellular uptake and cytotoxicity of medical nanoparticles, Int. J. Nanomed. 7 (2012) 5577-5591, doi:10.2147/IJN. S36111.

[70] C.A. Buckner, A.L. Buckner, S.A. Koren, M.A. Persinger, R.M. Lafrenie, Inhibition of cancer cell growth by exposure to a specific time-Varying electromagnetic field involves T-Type calcium channels, PLoS One 10 (2015), doi:10.1371/ journal.pone.0124136.

[71] M. Martínez-Carmona, D. Lozano, M. Colilla, M. Vallet-Regí, Lectin-conjugated pH-responsive mesoporous silica nanoparticles for targeted bone cancer treatment, Acta Biomater. 65 (2018) 393-404, doi:10.1016/j.actbio.2017.11.007.

[72] M. Mak, F. Spill, R.D. Kamm, M.H. Zaman, Single-cell migration in complex microenvironments: mechanics and signaling dynamics, J. Biomech. Eng. 138 (2016).

[73] J. Pijuan, C. Barceló, O. Maiques, D.F. Moreno, P. Sisó, R.M. Marti, A. Macià, A. Panosa, In vitro cell migration, invasion and adhesion assays: from cell imaging to data analysis, Front. Cell Dev. Biol. 7 (2019) 107.

[74] S. Tojkander, G. Gateva, P. Lappalainen, Actin stress fibers-assembly, dynamics and biological roles, J. Cell Sci. 125 (2012) 1855-1864.

[75] S.H. Lee, R. Dominguez, Regulation of actin cytoskeleton dynamics in cells, Mol. Cells. 29 (2010) 311-325, doi:10.1007/s10059-010-0053-8.

[76] B.H. Sung, X. Zhu, I. Kaverina, A.M. Weaver, Cortactin controls cell motility and lamellipodial dynamics by regulating ECM secretion, Curr. Biol. 21 (2011) 1460-1469.

[77] T. Ma, Z. Zhang, Y. Lu, Y. Zhang, D. Tao, Y. Liu, Y. Ma, CLOCK and BMAL1 stabilize and activate RHOA to promote F-actin formation in cancer cells, Exp. Mol. Med. 50 (2018) 1-15.
[78] M. Hou, X. Liu, J. Cao, B. Chen, SEPT7 overexpression inhibits glioma cell migration by targeting the actin cytoskeleton pathway, Oncol. Rep. 35 (2016) 2003-2010.

[79] D.M. Moran, C.G. Maki, Nutlin-3a induces cytoskeletal rearrangement and inhibits the migration and invasion capacity of p53 wild-type cancer cells, Mol. Cancer Ther. 9 (2010) 895-905, doi:10.1158/1535-7163.MCT-09-1220.

[80] W. Hui, S. Liu, J. Zheng, Z. Fang, Q. Ding, C. Feng, Nutlin-3a as a novel anticancer agent for adrenocortical carcinoma with CTNNB1 mutation, Cancer Med 7 (2018) 1440-1449, doi:10.1002/cam4.1431.

[81] O. Wu, X. Wang J. Liu, J. Zheng, Y. Liu, Y. Li, F. Su, W. Ou, R. Wang, Nutlin-3 reverses the epithelial-mesenchymal transition in gemcitabine-resistant hepatocellular carcinoma cells, Oncol. Rep. 36 (2016) 1325-1332, doi:10.3892/or. 2016.4920.

[82] A. Hatoum, R. Mohammed, O. Zakieh, The unique invasiveness of glioblastoma and possible drug targets on extracellular matrix, Cancer Manag. Res. 11 (2019) 1843-1855, doi:10.2147/CMAR.S186142.

[83] I. Restall, D.A. Bozek, C. Chesnelong, S. Weiss, H.A. Luchman, Live-Cell Imaging Assays to Study Glioblastoma Brain Tumor Stem Cell Migration and Invasion, J. Vis. Exp. (2018) 58152, doi:10.3791/58152.

[84] M. Solinas, P. Massi, V. Cinquina, M. Valenti, D. Bolognini, M. Gariboldi, E. Monti, T. Rubino, D. Parolaro, Cannabidiol, a non-psychoactive cannabinoid compound, inhibits proliferation and invasion in U87-MG and T98G glioma cells through a multitarget effect, PLoS One 8 (2013) e76918.

[85] S. Hirohashi, Inactivation of the E-cadherin-mediated cell adhesion system in human cancers, Am. J. Pathol. 153 (1998) 333-339, doi:10.1016/ S0002-9440(10)65575-7.

[86] Y. Iwadate, Epithelial-mesenchymal transition in glioblastoma progression, Oncol. Lett. 11 (2016) 1615-1620, doi:10.3892/ol.2016.4113. 